\title{
A Novel Role for Catalase B in the Maintenance of Fungal Cell-Wall Integrity During Host Invasion in the Rice Blast Fungus Magnaporthe grisea
}

\author{
Pari Skamnioti, Catherine Henderson, Ziguo Zhang, Zena Robinson, and Sarah Jane Gurr \\ Department of Plant Sciences, South Parks Road, University of Oxford, OX1 3RB, U.K. \\ Submitted 13 October 2006. Accepted 11 December 2006.
}

\begin{abstract}
Asexual spores of the rice blast fungus germinate to produce a specialized and melanized infection structure, the appressorium, which is pivotal to successful plant penetration. To investigate whether Magnaporthe grisea counteracts the toxic burst of $\mathrm{H}_{2} \mathrm{O}_{2}$ localized beneath the site of attempted invasion, we examined the temporal expression of five candidate antioxidant genes. Of these, the putatively secreted large subunit catalase CATB gene was 600-fold up-regulated in vivo, coincident with penetration, and moderately up-regulated in vitro, in response to exogenous $\mathrm{H}_{2} \mathrm{O}_{2}$. Targeted gene replacement of $C A T B$ led to compromised pathogen fitness; the $c a t B$ mutant displayed paler pigmentation and accelerated hyphal growth but lower biomass, poorer sporulation, fragile conidia and appressoria, and impaired melanization. The catB mutant was severely less pathogenic than Guy 11 on barley and rice, and its infectivity was further reduced on exposure to $\mathrm{H}_{2} \mathrm{O}_{2}$. The wild-type phenotype was restored by the reintroduction of $C A T B$ into the $c a t B$ mutant. We found no evidence to support a role for CATB in detoxification of the hostderived $\mathrm{H}_{2} \mathrm{O}_{2}$ at the site of penetration. Instead, we demonstrated that CATB plays a part in strengthening the fungal wall, a role of particular importance during forceful entry into the host.
\end{abstract}

Additional keywords: hydrogen peroxide, melanin, ROS, stress, turgor.

All aerobes face exposure to endogenously derived reactive oxygen species (ROS), formed by the incomplete reduction of molecular oxygen during respiration and metabolism. In addition, pathogens must contend with the exogenous oxidative burst generated by the host during invasion (Aguirre et al. 2005; Torres et al. 2006). Irrespective of their origin, ROS can oxidize cell components such as DNA, protein, and lipids, thus damaging cell organelles and compromising cell function. To counteract these potentially lethal effects, cells balance ROS levels in a variety of ways, such as boosting the antioxidant

Corresponding author: S. J. Gurr; E-mail: sarah.gurr@plants.ox.ac.uk; Telephone: (+44) 1865275813.

Pari Skamnioti and Catherine Henderson contributed equally to this work.

Current address for Z. Zhang: Department of Agricultural Sciences, The Royal Veterinary and Agricultural University, Thorvaldsensvej 40, 1871 Frederiksberg C, Denmark.

* The $\boldsymbol{e}$-Xtra logo stands for "electronic extra" and indicates that Figures $3,5,6,8$, and 9 appear in color online. enzyme activities of superoxide dismutase (SOD), which converts superoxide to hydrogen peroxide $\left(\mathrm{H}_{2} \mathrm{O}_{2}\right)$, and catalase, which converts $\mathrm{H}_{2} \mathrm{O}_{2}$ to water and molecular oxygen.

In plants, the accumulation of ROS at the site of pathogen invasion is thought to have an antimicrobial, cell-wall strengthening or signaling role (Lamb and Dixon 1997; Mellersh et al. 2002; Torres et al. 2005, 2006). In animals, pathogen attack heralds ROS accumulation and triggers innate immunity (Giles et al. 2006). There is some evidence to suggest that pathogens survive the harsh environment of the host using their antioxidant defense systems for self-protection or detoxification of host-derived ROS. For example, the necrotrophic fungal pathogen Botrytis cinerea has been shown to suppress defenserelated $\mathrm{O}_{2}^{-}$production in bean leaf tissue (Unger et al. 2005).

Fungi carry varying numbers of catalases with seemingly disparate cellular functions. In Aspergillus fumigatus, which has two mycelial and one conidial catalase, deletion of a single catalase had no effect on virulence, but a mutant lacking both mycelial catalases showed reduced virulence (Calera et al. 1997; Paris et al. 2003). The single catalase in Candida albicans plays a particular role in protecting the fungus from peroxide stress and neutrophil damage (Nakagawa et al. 2003; Wysong et al. 1998). In Cryptococcus neoformans, deletion of any one of four catalases or quadruple gene disruption gave mutants showing no loss of pathogenicity in mice (Giles et al. 2006). In phytopathogenic fungi, catalase knock-out mutants in Botrytis cinerea (Schouten et al. 2002), Cochliobolus heterostrophus (Robbertse et al. 2003), and Claviceps purpurea (Garre et al. 1998) are as virulent as the wild-type strains. However, in Claviceps purpurea, deletion of the transcription factor CPTF1, which encodes a protein controlling overall catalase activity, had a significant impact on virulence (Nathues et al. 2004). Lastly, there is evidence that barley powdery mildew, Blumeria graminis f. sp. hordei, scavenges host-derived $\mathrm{H}_{2} \mathrm{O}_{2}$ specifically at sites of fungal invasion, and the expression and secretion of a catalase coincides temporally and spatially with this (Zhang et al. 2004).

Magnaporthe grisea causes the most destructive disease of cultivated rice world wide as well as infecting a wide range of grass hosts, including barley, wheat, and finger millet (Talbot 2003). Disease is spread by prolific numbers of asexual conidia that are discharged from sporophores. Given the correct cues, a tube emerges from the spore and swells at its distal tip to form a dome-shaped appressorium (de Jong et al. 1997; Howard and Valent 1996; Howard et al. 1991). Subsequently, glycerol levels rise within the appressorium to around $3 \mathrm{M}$ and facilitate the generation of sufficient turgor pressure $(8 \mathrm{MPa})$ for the emerging penetration peg to breach the host cuticle and so effect infection (Howard et al. 1991; Talbot 2003). The 
appressorium cell wall is an ordered chitin-rich structure (Bourett and Howard 1990; Tucker and Talbot 2001) that carries a veneer of melanin on its inner surface. In $M$. grisea, melanin is made via a pentaketide pathway leading to 1,8 dihydroxynapthalene (DHN), which is polymerized by phenol oxidases to form melanin (Kurahashi 2001; Thompson et al. 2000). Several M. grisea mutants, such as albino, buff, and rosy (Howard et al. 1991; Money and Howard 1996), carry specific lesions in melanin biosynthesis and are nonpathogenic because the appressoria are 'leaky' (Talbot 2003) and cannot support high turgor pressures.

Much research has focused on the study of signal transduction pathways that regulate appressorium formation in $M$. grisea (Talbot 2003) and on the various biochemical processes that underpin the generation of turgor (Wang et al. 2005). However, save for the work of Tucker and associates (2004) on the putative redox-sensing wall-associated metallothionein 1 (MMT1) and the observation that many antioxidant genes are abundant in the published $M$. grisea genome sequence (Dean et al. 2005), little is known about antioxidant enzymes in this fungus.

The starting point for our investigation was the search for genes whose products may protect against or detoxify the host oxidative burst, as visualized in rice (Pasechnik et al. 1998). We showed that the gene encoding the large subunit catalase, CATB, is highly up-regulated in vivo, coincident with penetration. The loss of function mutant has compromised wall integrity and this, in turn, leads to attenuated virulence. Thus, CATB plays a novel and pivotal role in the infection process of M. grisea.

\section{RESULTS}

\section{$C A T B$ expression is elevated}

during penetration in vivo and in response to $\mathrm{H}_{2} \mathrm{O}_{2}$ in vitro.

The $M$. grisea genome contains two true heme catalases, catalase A (CATA) and catalase B (CATB), plus catalase peroxidase A (CPXA) and catalase peroxidase $B(C P X B)$. The cytochrome $\mathrm{c}$ peroxidase $\mathrm{B}$ (CCPB) sequence was also identified. To assess whether the expression patterns of any of these genes suggest their involvement in the management of the host oxidative burst, quantitative real time reverse transcriptase polymerase chain reaction (qrtRT-PCR) was performed on wild-type strain Guy11 inoculated onto barley leaves. Transcript levels were monitored in ungerminated conidia $(0 \mathrm{~h}$ postinoculation [hpi]), germlings stripped from barley leaves during appressorium formation (5 hpi), coincident with penetration (12 hpi), and during subcuticular growth (20 hpi). Figure 1A shows the dramatic upregulation of $C A T B$ gene expression at $12 \mathrm{hpi}$, when transcript abundance is around 600-fold higher than the level in ungerminated conidia. At the same timepoint, $C P X A$ and $C P X B$ showed a small increase in expression of about twofold, as compared with that found at 0 hpi (Fig. 1C and D), whereas $C A T A$ and $C C P B$ transcripts are most abundant in ungerminated spores (Fig. $1 \mathrm{~B}$ and $\mathrm{E}$ ). As catalases are potent $\mathrm{H}_{2} \mathrm{O}_{2}$ detoxifying enzymes, we also looked at $C A T A$ and $C A T B$ transcript levels following exposure to varying concentrations of $\mathrm{H}_{2} \mathrm{O}_{2}$ in vitro. CATA expression varied little with time and $\mathrm{H}_{2} \mathrm{O}_{2}$ concentration, whereas $C A T B$ transcript abundance showed a moderate increase, in line with increasing $\mathrm{H}_{2} \mathrm{O}_{2}$ concentrations (Fig. $1 \mathrm{~F}$ and $\mathrm{G}$ ). Collectively, the upregulation of $C A T B$ in vivo coincident with penetration of the host and the $\mathrm{H}_{2} \mathrm{O}_{2}$ dose-dependent rise in expression in vitro implies that CATB plays a role in the infection process that may be associated with detoxification of the host oxidative burst.
Targeted replacement of $C A T B$ in $M$. grisea and complementation of $c a t B$ mutant with $C A T B$.

To determine the functional significance of the $C A T B$ gene in $M$. grisea, a deletion mutant was created by replacing the $C A T B$ coding region with a bacterial hygromycin phosphotransferase resistance gene (Fig. 2A). The gene replacement vector was introduced into rice pathogenic strain Guy11 and hygromycin-resistant transformants were selected. Southern blot analysis confirmed successful gene replacement (Fig. 2B, transformant T6), with a single integration event (Fig. 2C). Verification that $C A T B$ gene replacement had resulted in gene inactivation was demonstrated by RT-PCR, which showed complete absence of $C A T B$ transcript in the catB mutant (Fig. $2 \mathrm{D})$, as compared with persistent $\beta-T U B$ gene expression. To confirm that the various phenotypes shown by the $\operatorname{cat} B$ mutant were associated with gene inactivation, the $C A T B$ gene was reintroduced in a plasmid conferring resistance to sulphonylurea (Carroll et al. 1994). A transformant carrying a singlecopy integration of the $C A T B$ gene was identified by Southern blot analysis and designated catB/CATB (data not shown).

\section{Loss of CATB does not lead}

to overexpression of $C A T A$ or related antioxidant genes.

We investigated whether deletion of $C A T B$ affects expression of $C A T A, C P X A, C P X B$, and $C C P B$ by monitoring transcript activity during germling morphogenesis in the $c a t B$ mutant (Fig. 1B through E). There was little overall change in the pattern of transcript accumulation in $c a t B$ and Guy11. The exception was a moderate twofold upregulation of $C C P B$ in ungerminated conidia as compared with Guy11. These data suggest CATA, CPXA, CPXB, or CCPB are unlikely to compensate for the absence of CATB and point towards a distinct role for CATB in $M$. grisea pathogenesis.

\section{Loss of CATB function attenuates virulence.}

To determine the role of CATB during disease progression, blast-susceptible barley cultivar Pastoral and rice cultivar CO39 were inoculated with wild-type Guy11, catB mutant, and the recomplemented strain $c a t B / C A T B$. Mean lesion densities on barley were as follows: Guy11, $17.8 \pm 7.8$; $c a t \mathrm{~B}, 10.6 \pm 6.3$; and $c a t B / C A T B, 16.2 \pm 6$. Mean lesion densities on rice were Guy11, $40.26 \pm 18.7$; catB, $14.46 \pm 11.5$; and catB/CATB, $37.1 \pm 8.5$. In summary, the $c a t B$ mutant gave rise to around $40 \%$ fewer lesions than did Guy11 on barley (Fig. 3A and C, $P$ $<0.001$ ) and $65 \%$ fewer lesions on rice (Fig. 3B and D, $P<$ $0.001)$. This demonstrated that virulence is attenuated in the $c a t B$ strain but full virulence is restored in strain $c a t B / C A T B$ (Fig. 3A).

\section{Loss of CATB function reduces conidiation} and compromises hyphal development in vitro.

Mutant colonies show a paler pigmented phenotype than the darker gray of Guy11. The catB mutant shows reduced sporulation. For example, at 16 days postinoculation (dpi), the mutant produced 30-fold fewer spores than Guy11 (Fig. 4A). Conidiation was restored to wild-type levels in the recomplemented strain catB/CATB (Fig. 4A). The collapsed sporophore and hyphae in the $c a t B$ mutant contrast with the more turgid sporophore and hyphae seen in Guy11 (Fig. 4B).

\section{Loss of CATB function impairs penetration.}

We compared $c a t B$ mutant and Guy11 germling differentiation on inductive hydrophobic coverslips, which permit normal appressorium formation in Guy11. Both strains form melanized appressoria (Fig. 5A). Appressorium-mediated cuticle penetration was assessed by counting the number of appressoria forming successful penetration hyphae on barley epidermal 

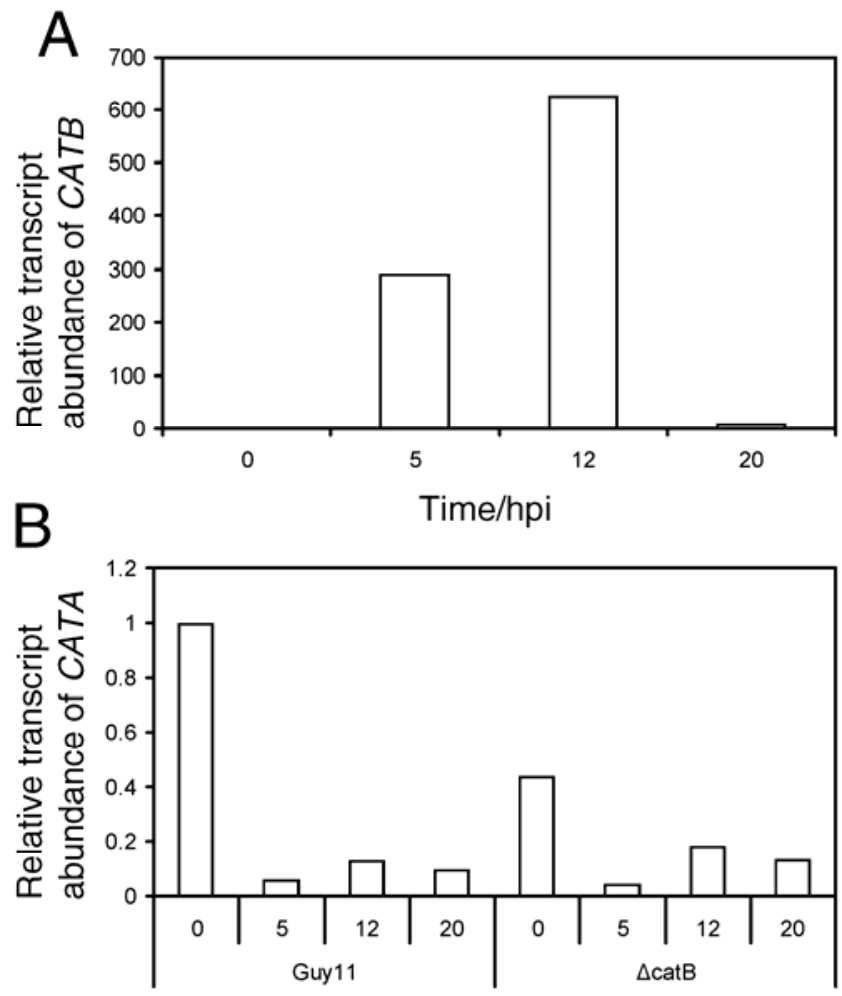

Time/hpi

D
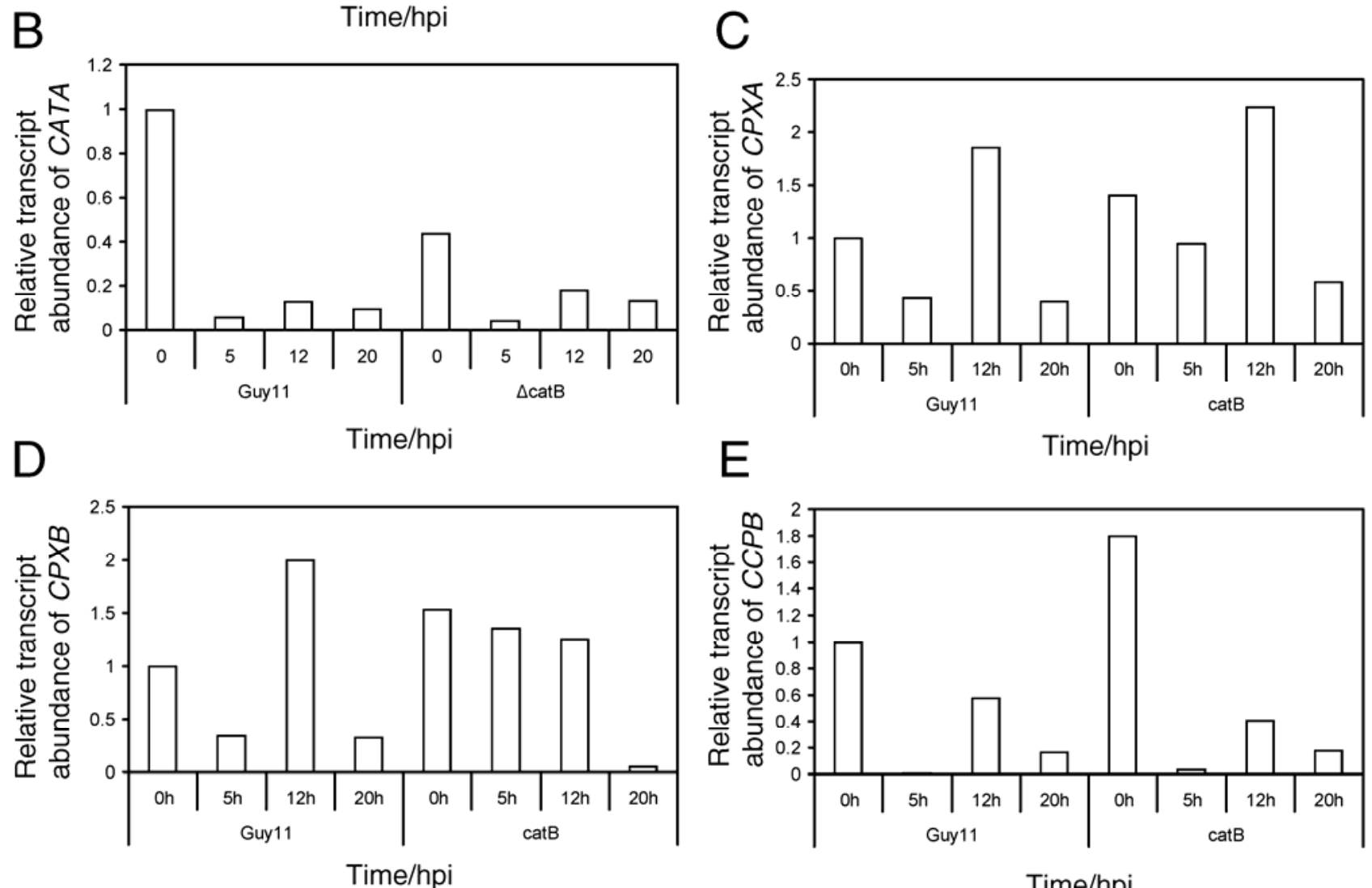

$\mathrm{F}$

G

Time/hpi


Fig. 1. Relative transcript abundance of A, Magnaporthe grisea wild-type strain Guy11 CATB, B, Guy 11 and catB mutant $C A T A, \mathbf{C}, C P X A, \mathbf{D}, C P X B$, and $\mathbf{E}, C C P B$ following fungal differentiation during infection of barley leaves at $0,5,12$, and $20 \mathrm{~h}$ postinoculation (hpi) and of $\mathbf{F}$, Guy $11 C A T B$ and $\mathbf{G}, C A T A$ expression levels in vitro following exposure to 1 to $5 \mathrm{mM} \mathrm{H}_{2} \mathrm{O}_{2}$ for up to $3 \mathrm{~h}$. Each profile was normalized against $\beta$-TUB and was calibrated to 0-hpi, ungerminated conidia. Polymerase chain reaction assays were carried out in triplicate. Template controls and no-reverse-transcriptase controls did not show amplification. 
peels. The penetration success rates were twofold higher in Guy11 $(61 \%)$ than catB $(32 \%, P<0.05)$, demonstrating that the mutant is less able to breach the host than Guy11.

\section{Loss of CATB function impairs management of host-derived $\mathrm{H}_{2} \mathrm{O}_{2}$ oxidative stress.}

The effect of exposure to $\mathrm{H}_{2} \mathrm{O}_{2}$ on $c a t B$ and Guy11 was investigated in vitro and in vivo. The mutant $c a t B$ showed accelerated growth on agar plate assays carrying 5 to $20 \mathrm{mM} \mathrm{H}_{2} \mathrm{O}_{2}$ (Fig. 5B and C) compared with that of Guy11 and catB/CATB. However, liquid-culture growth assays revealed $c a t B$ had significantly less biomass than Guy 11 (and catB/CATB) at equivalent concentrations of $\mathrm{H}_{2} \mathrm{O}_{2}$ (Fig. 5D)

We investigated whether $c a t B$ or, indeed, Guy11 made appressoria when exposed to exogenous $\mathrm{H}_{2} \mathrm{O}_{2}$ throughout germling differentiation on hydrophobic plastic coverslips. Around $75 \%$ of $c a t B$ and Guy11 germlings formed melanized appressoria in the presence of $1 \mathrm{mM} \mathrm{H}_{2} \mathrm{O}_{2}$. However, at $10 \mathrm{mM}$ $\mathrm{H}_{2} \mathrm{O}_{2}, 80 \%$ of catB germlings formed melanized appressoria, while only $1 \%$ Guy 11 germlings progressed to this stage of development, with the majority forming short abnormal germ tubes (Fig. 5A).

We assessed whether the exposure of spores to exogenous $\mathrm{H}_{2} \mathrm{O}_{2}$ affects appressorium function and, thus, infectivity. Treatment of spores with 1 or $10 \mathrm{mM} \mathrm{H}_{2} \mathrm{O}_{2}$ for $1 \mathrm{~h}$ prior to infection of barley plants revealed an immediate and dosedependent decline in infectivity of catB mutant in increasing concentrations of $\mathrm{H}_{2} \mathrm{O}_{2}(P<0.001)$ (Fig. 5E). By contrast, Guy11 was not significantly changed in its capacity to infect barley after exposure to $1 \mathrm{mM} \mathrm{H}_{2} \mathrm{O}_{2}$ but was reduced in virulence after treatment with $10 \mathrm{mM} \mathrm{H}_{2} \mathrm{O}_{2}(P<0.05)$. This dramatic reduction in infectivity of $c a t B$ in vivo points to a role for CATB in protecting $M$. grisea from host-imposed oxidative stress during invasion.

\section{Loss of CATB function does not influence the accumulation or detoxification of the host-imposed oxidative burst.}

First, we monitored the oxidative burst in barley in response to infection by visualizing the cumulative accumulation of $\mathrm{H}_{2} \mathrm{O}_{2}$ by DAB (3,3'-diaminobenzidine) staining (Fig. 6A, i and ii). Staining was never observed beneath germ tubes or spores, whereas the frequency of polymerized DAB beneath Guy11 and $c a t B$ mutant appressoria increased significantly between 4 and $5 \mathrm{hpi}$, rising from $5 \%$ to $60 \%$. The frequencies of DAB staining beneath Guy 11 and $c a t B$ appressoria were not significantly different at either 5 or 12 hpi (Fig. 6B). Second, we used a modified DAB- $\mathrm{H}_{2} \mathrm{O}_{2}$ assay (Zhang et al. 2004) to reveal areas of putative fungal scavenging of $\mathrm{H}_{2} \mathrm{O}_{2}$ about appressoria (Fig. 6A, iii). There was no significant difference in the numbers of zones of clearing, which occurred beneath around $38 \%$ of appressoria, or their diameters, which measured $90 \pm 11$ $\mu \mathrm{m}^{2}$, between Guy11 and $\operatorname{catB} \mathrm{H}_{2} \mathrm{O}_{2}$ appressoria at $12 \mathrm{hpi}$. These findings provoke speculation about an alternative role for CATB in the management of $\mathrm{H}_{2} \mathrm{O}_{2}$-imposed stress.

\section{Loss of CATB function does not affect conidial longevity or sexual fecundity.}

To assess whether CATB plays a role in spore survival and longevity, we compared the infection rates on barley inoculated with $c a t B$ mutant or Guy11 conidia, harvested from 7- and 17day-old plate-grown cultures. The $c a t B$ mutant was severely impaired in its ability to cause disease lesions compared with that of Guy11. However, there was no statistically significant reduction in the disease levels caused between 7- and 17-day cat $B$ conidia nor between 7- and 17-day Guy 11 conidia $(P>$ 0.05) (data not shown), showing that reduced virulence in cat $B$ is not due to compromised spore survival. Sexual crosses with opposite mating-type strain TH3 showed that loss of CATB does not affect the formation of perithecia or ascospores.

Loss of CATB function compromises fungal wall integrity.

We compared the relative integrity of the conidial, mycelial, and appressorium cell walls. Under hyperosmotic stress, cat $B$ conidia collapsed at lower concentrations than did Guy11 conidia. At $1 \mathrm{M}$ glycerol, collapse rates were $17 \%$ for catB, $1 \%$ for Guy 11 , and $2 \%$ for catB/CATB; at $2 \mathrm{M}$ glycerol, $59 \%$ for catB, $19 \%$ for Guy 11 , and $16 \%$ for catB/CATB; at $3 \mathrm{M}$ glyc-

A

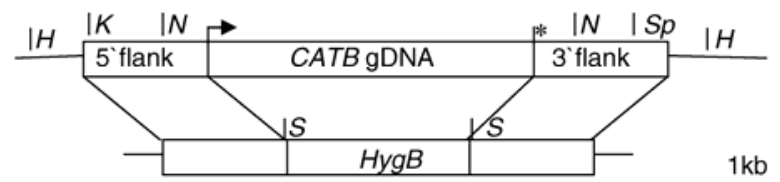

B kb ladders Guy11 T3 T6 T10
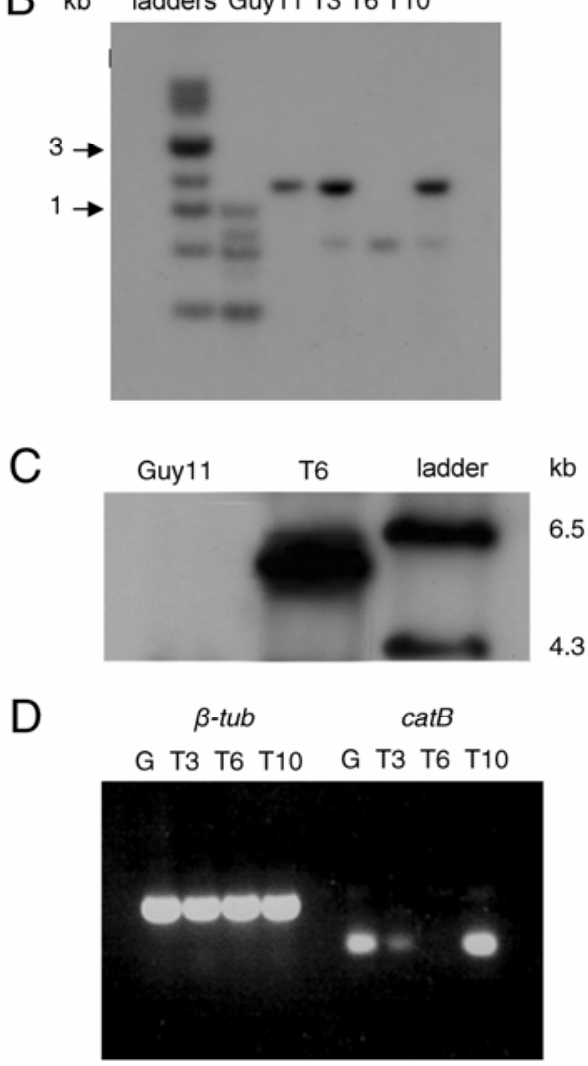

Fig. 2. Targeted gene replacement and complementation of Magnaporthe grisea $C A T B$. A, Organization of the $C A T B$ locus, before and after homologous recombination. Translation start (arrow) and stop (asterisk) codons for $C A T B$ gene. The restriction enzymes are $\operatorname{HindIII}(H), K p n I(K), N d e \mathrm{I}$ $(N)$, SalI $(S)$, and SpeI $(S p)$. Scale bar $=1 \mathrm{~kb}$. B, Southern blot analysis of DNA from wild-type strain Guy11 and selected transformants digested with $N d e$ I and hybridized to a 1,946-bp NdeI fragment containing the $C A T B$ gene. Guy11 and putative transformants T3 and T10 contain the intact $C A T B$ gene. Transformant T6 does not hybridize to the native $C A T B$ gene but to a 1,122-bp fragment, resulting from the gene replacement by the introduction of the hygromycin B-selectable marker. C, Southern blot analysis of DNA from Guy11 and T6 transformant digested with HindIII and hybridized to the 1.4-kb hygromycin B gene. Only one band of the correct size $(5.7 \mathrm{~kb})$ is detected in the T6 transformant, confirming the single integration of the knockout plasmid. D, Reverse transcript-polymerase chain reaction used to monitor the expression of $C A T B$ in Guy $11(\mathrm{G}), \mathrm{T} 3$, T6 (catB mutant), and T10 transformants, using $\beta-T U B$ as control. Gene replacement in T6 has resulted in complete loss of catB transcript. 
erol, $90 \%$ for $c a t B, 40 \%$ for Guy 11 , and $37 \%$ for catB/CATB. Exposure of mycelium to Glucanex reveals the catB mutant releases $60 \%$ more protoplasts than does Guy11 and 52\% more than $c a t B / C A T B$, by $3 \mathrm{~h}$ posttreatment with this cellwall-degrading enzyme (Fig. 7A). We compared the robustness of $c a t B$ and Guy11 appressorium walls by incipient cytorrhysis. At $24 \mathrm{~h}$, appressoria formed on hydrophobic coverslips were exposed to 1 to $4 \mathrm{M}$ glycerol. The $c a t B$ mutant was hypersensitive to this treatment; for example, at $2 \mathrm{M}$ glycerol, twice as many catB appressoria collapsed as did Guy11 appresoria $(P<0.05)$ (Fig. 7B). Together, these data point to a defect in prepenetration germling growth, notably in wall integrity, upon deletion of $C A T B$.

We evaluated the structural integrity of the mutant cell wall by comparing the effects of various inhibitors of cell-wall turnover on Guy11 and the catB mutant. Comparative growth assays showed no difference in sensitivity of Guy11 and $c a t B$ strains to exposure to sodium dodecyl sulfate (SDS) (0.0001 to $0.05 \%$ ), to exposure to the chitin synthase inhibitors nikkomycin Z (Cabib 1991) and polyoxin D (Debono and Gordee 1994 ) or the 1,3-beta glucan synthase inhibitor caspofungin (Kurtz et al. 1996) at rates up to $100 \mu \mathrm{g} \mathrm{ml}^{-1}$, or to exposure to the fluorochrome chitin-binding dye Calcofluor White (data not shown) at rates up to $2.5 \mathrm{mg} \mathrm{ml}^{-1}$. This demonstrates that while catB walls are weaker than those of Guy11, the chitin and glucan synthesis inhibitors and wall modifiers do not differentially affect strain growth.

To gain insight into the cause of the compromised structural integrity of the catB mutant, we used Raman spectroscopy to compare the spectral profiles of the $c a t B$ and Guy11 cell walls.
Raman shift wave number $1,085 \mathrm{~cm}^{-1}$, assigned as a $\mathrm{C}-\mathrm{O}$ bond stretch (Maquelin et al. 2002), reveals a clear difference between the strain profiles, with $c a t B$ showing a peak intensity considerably greater than Guy11 (Fig. 8). The peak intensity demonstrates a greater prevalence of $\mathrm{C}-\mathrm{O}$ functional groups (e.g., C-OH) such that the oxidation status of catB mutant may be greater than that of Guy11.

\section{Loss of CATB function impairs melanization.}

The paler pigmented phenotype of the catB mutant suggests that melanin biosynthesis is compromised. We compared the effect of a melanin biosynthetic reductase inhibitor, the fungicide Tricyclazole (TCZ), at concentrations of 1 to $150 \mu \mathrm{g} \mathrm{ml}^{-1}$, on $c a t B$ and Guy11 and catB/CATB colony growth. TCZ at a concentration of $100 \mu \mathrm{g} \mathrm{ml}^{-1}$ (Fig. 9A) consistently reduced the growth of $c a t B$ by some 1.7 -fold more than that of Guy11 $(P<0.05)$. We compared laccase activity, hypothesizing that polyphenoloxidase function may be impaired in $c a t B$. The oxidation of the laccase substrate 2, 2'-azino-di-3-ethylbenzathiazoline-6-sulfonate (ABTS) in plate assays showed that laccase activity was reduced in $c a t B$, with a halo consistently 1.4 times smaller than the darker-staining Guy11 $(P<0.05)$ (Fig. 9B). Since copper sulphate is known to stimulate melanogenesis through laccase activity, we looked at the effect of copper sulphate on colony growth. Exposure of the two strains to 1 to 5 $\mathrm{mM}$ copper sulphate revealed that catB consistently grew better in the presence of copper concentrations than Guy11. For example, catB grew 1.1-fold faster than Guy11 in $1 \mathrm{mM}$ copper sulphate and 1.4-fold faster in $5 \mathrm{mM}$ copper sulphate than did Guy11 and catB/CATB $(P<0.05)$ (Fig. 9C). Moreover,
A

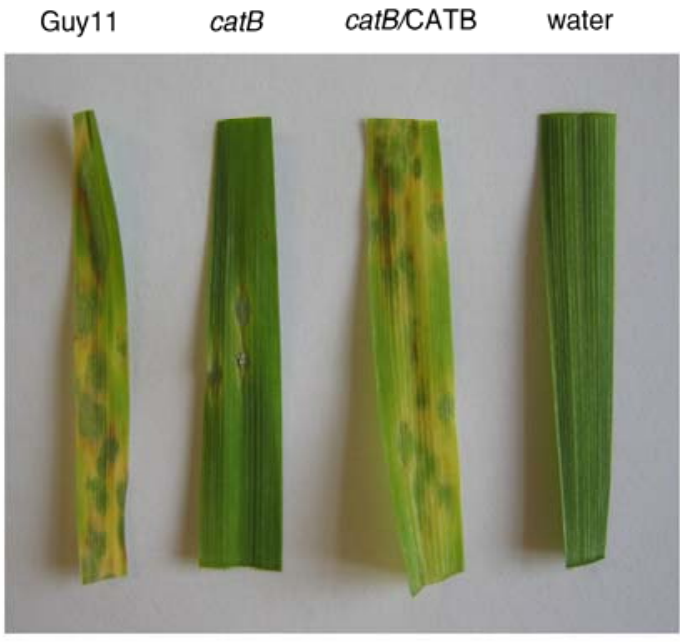

\section{C}

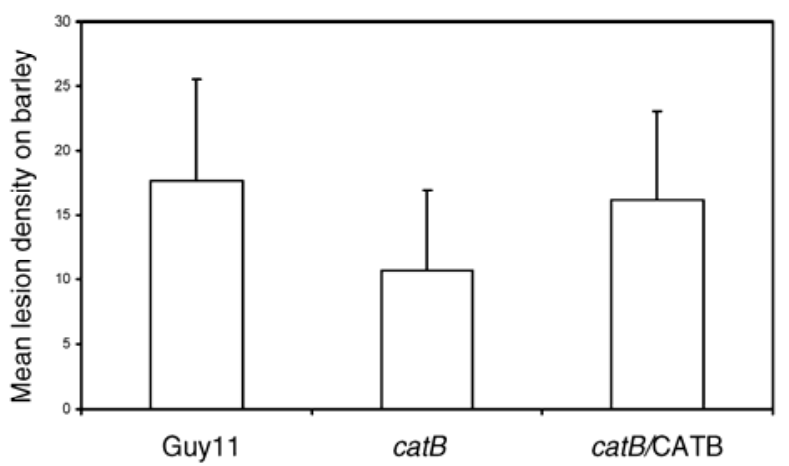

B
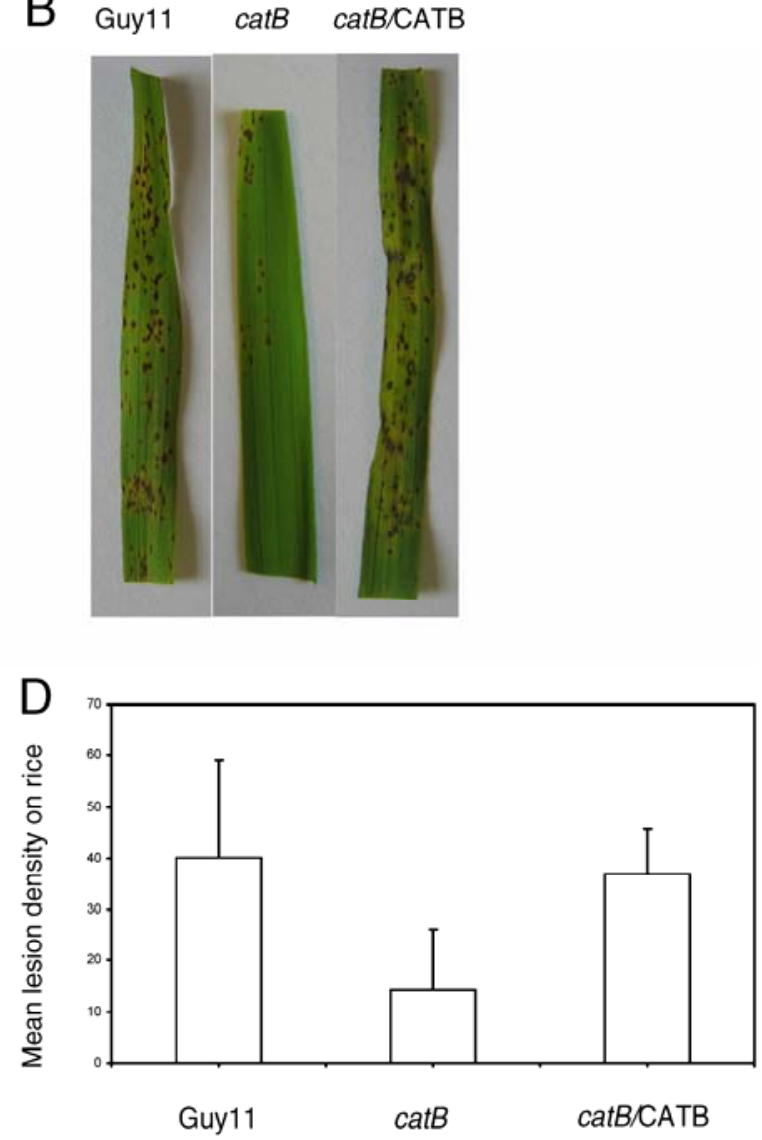

Fig. 3. Pathogenicity of Guy 11 , catB, and $c a t B / C A T B$ on barley and rice. A, Barley and $\mathbf{B}$, rice plants were sprayed with conidial suspensions $\left(10^{4}\right.$ spores $\mathrm{ml}^{-1}$ ) in $0.25 \%$ gelatin. At 6 days postinoculation, 40 leaves picked at random were scored for the number of lesions on 5-cm leaf lengths, in three independent experiments. Mean lesion density recorded $\mathbf{C}$, on barley and D, on rice. Error bars represent the standard deviations of the means. 
addition of high concentrations of copper sulphate to ABTS plates gave rise to laccase haloes of equivalent diameter with $\triangle c a t B$ and Guy11, suggesting that high exogenous concentrations of copper may boost laccase activity in the mutant (Fig. 9D). Thus, these data suggest that CATB plays a role in the melanization of the fungal cell wall.

\section{DISCUSSION}

\section{Fungal catalases.}

Recent phylogenetic analysis provides some insight into the origin of fungal catalases (Giles et al. 2006; Johnson et al. 2002). Most recently, Giles and associates (2006) gathered the catalases into four distinct clades, i.e., clade $\mathrm{P}$ (peroxisomal catalase), clade C (cytoplasmic catalase), clade A (spore-specific catalase), and clade B (secreted catalase). They speculated that ancestral fungi probably possessed spore-specific, peroxisomal and cytoplasmic catalases but that the secreted catalases, which exist only in euascomycete fungi, arose later. The $M$. grisea genome database yielded two catalase-peroxidase sequences and single copies of catalase A and B. No peroxisomal catalase-like sequence was found. The CATA and CATB sequences from $M$. grisea are homologous to large subunit monofunctional catalases. Within the large subunit enzyme group, those with $\mathrm{N}$-terminal signal peptides, such as $M$. grisea and Blumeria graminis CATB (Zhang et al. 2004), Neurospora crassa CAT3 (Michan et al. 2003), and Aspergillus nidulans CATB (Kawasaki and Aguirre 2001), cluster closely together, while $M$. grisea CATA falls in a branch with other putatively nonsecreted fungal catalases alongside $N$. crassa CAT1 and A. nidulans CATA (Giles et al. 2006).

\section{Temporal expression of catalases and} other genes encoding putative antioxidant genes.

Of the various patterns of temporal expression of $C A T A$, $C A T B, C P X A, C P X B$, and $C C P B$ genes during germling differentiation on barley leaves, most notable was the peak in $C A T B$ transcript accumulation at the mature appressorium stage. This coincided with the host burst of $\mathrm{H}_{2} \mathrm{O}_{2}$, as evidenced by DAB staining of the barley or rice and fungus interface (Pasechnik et al. 1998). No such detailed transcript data is available for the early stages of germling morphogenesis of other phytopathogenic fungi. However, in the necrotroph $B$. cinerea, expression of the $C A T B$ gene is up-regulated during host colonization (Schouten et al. 2002), which was not the case for rice blast infection. $M$. grisea $C A T B$ transcript abundance increased also in vivo immediately following exogenous application of $\mathrm{H}_{2} \mathrm{O}_{2}$, in a dose-dependent manner, albeit to a lower level than in vitro. This finding hints at the importance of the host in triggering $C A T B$ expression in planta.

The observation that $C A T B$ transcripts were significantly enhanced in mature appressorium-stage germlings coincident with host penetration in Guy11 provoked the question as to whether genes encoding other antioxidant enzymes would compensate by boosting their own expression levels in the $c a t B$ knockout mutant. However, no dramatic stage-specific increases (i.e., greater than twofold) in transcript abundance of $C A T A, C P X A, C P X B$, and $C C P B$ were recorded in the $c a t B$ mutant, suggesting that CATB plays a distinct role in $M$. grisea and that functional redundancy between CATB and these proteins is unlikely.

Expression of CATA in the filamentous fungi A. nidulans and $A$. fumigatus and of the homologous nonsecreted catalase CAT1 in $N$. crassa is known to be spore-specific (Navarro et al. 1996; Paris et al. 2003) or elevated in conidia (Michan et al. 2002). This may be the case for $M$. grisea CATA, in which transcript abundance is elevated in ungerminated spores but is not altered by treatment with exogenous $\mathrm{H}_{2} \mathrm{O}_{2}$. M. grisea CATA may, therefore, be developmentally regulated to specifically protect conidia from endogenously-derived oxidative stress during metabolism, as has been found during $N$. crassa conidiation (Lledias et al. 1999; Peraza and Hansberg 2002).

\section{The role of CATB in pathogenesis.}

$C A T B$ gene ablation gave a mutant that caused disease of half the severity of its wild-type counterpart Guy11 on rice and barley. Appressorium-mediated cuticle penetration rates were also significantly reduced in the mutant compared with that of Guy11. The native CATB emerges, therefore, as a significant virulence determinant in successful rice blast infection. This is at variance with what has been found in other phytopathogenic fungi studied.

The $M$. grisea $c a t B$ mutant phenotype displayed several unusual growth characteristics. Compared with the wild-type

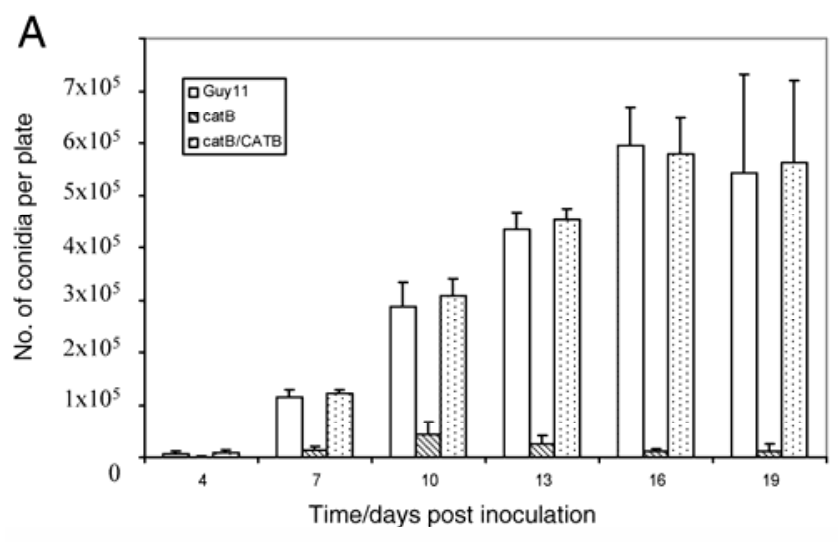

B
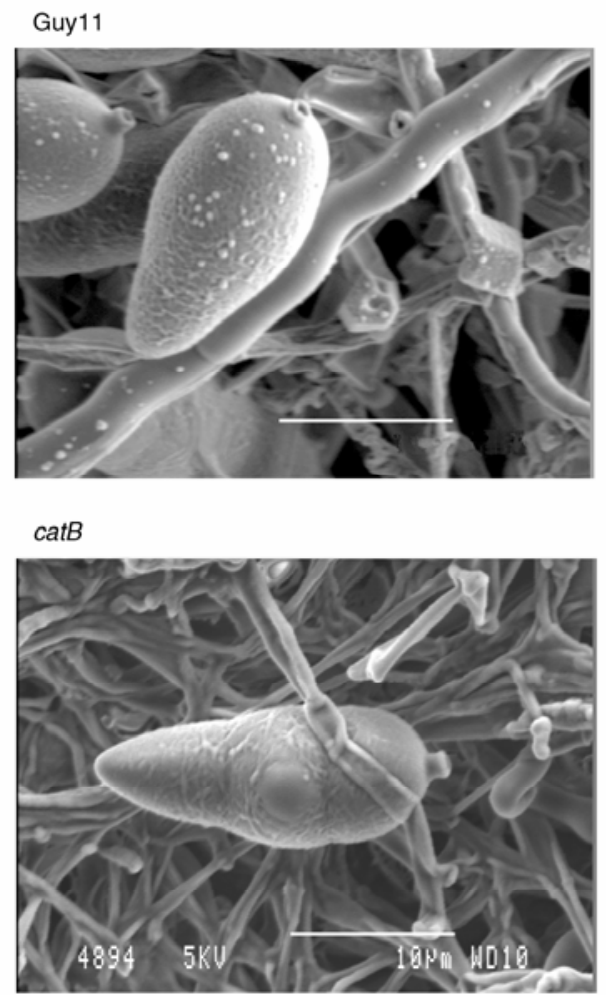

Fig. 4. Conidiation and hyphal morphology of Guy11 and catB. A, Comparison of the number of conidia produced by Guy 11, catB, and catB/CATB on solid medium (points are from three replicates). B, Scanning electrom microscopy of Guy 11 and $c a t B$ showing conidium and turgid or collapsed hyphae. Scale bar $=10 \mu \mathrm{m}$. 
strain, the paler catB mutant showed reduced sporulation, conidia and appressoria more prone to collapse under hyperosmotic stress, and accelerated release of protoplasts. Most pronounced of all visible characteristics, however, was the more rapid radial growth of the $\triangle c a t B$ mutant in vitro upon exposure to exogenous concentrations of $\mathrm{H}_{2} \mathrm{O}_{2}$ than that seen in Guy11. However, the biomass of these mutant colonies was less than that of their wild-type counterparts. This particular
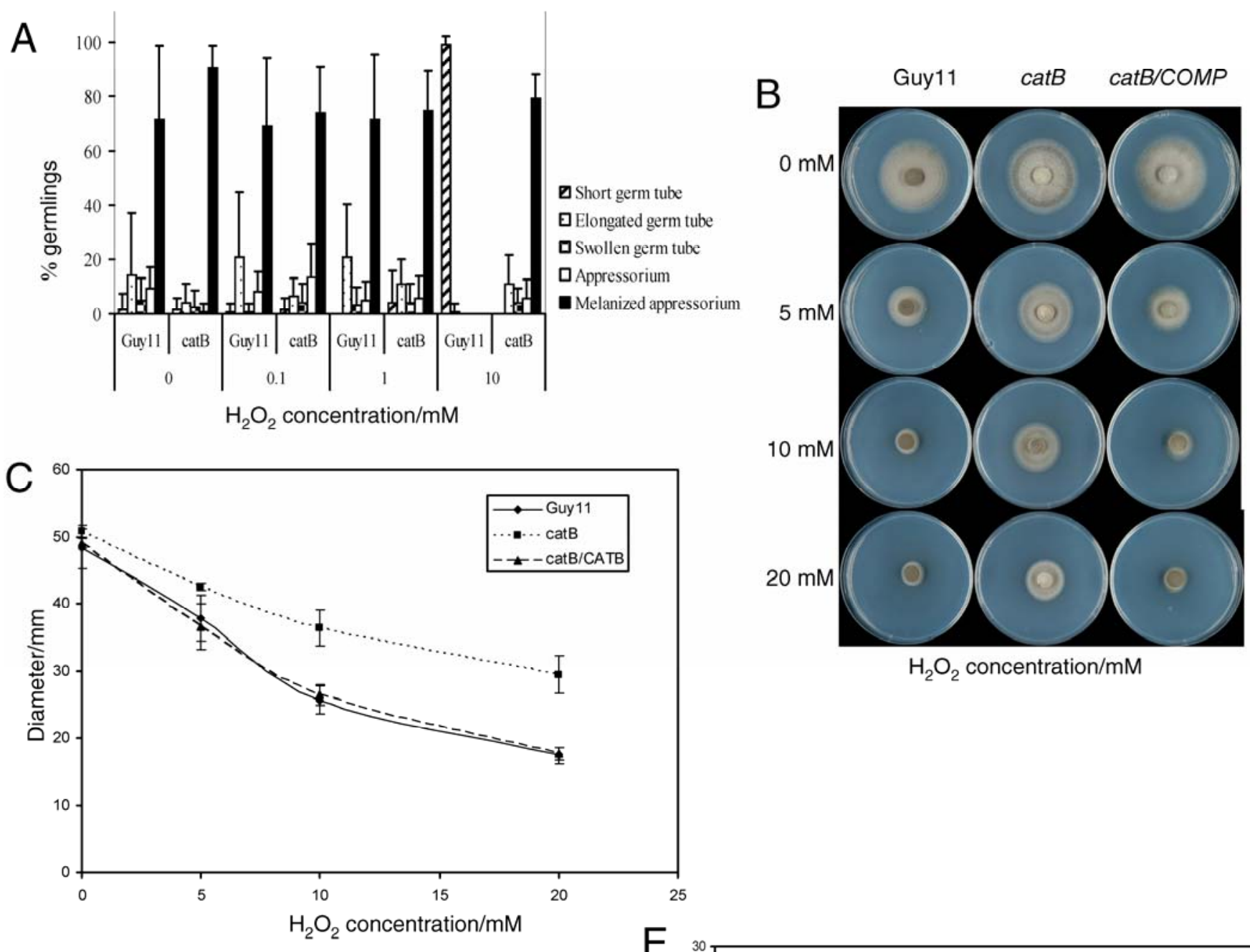

$\mathrm{H}_{2} \mathrm{O}_{2}$ concentration/mM

D

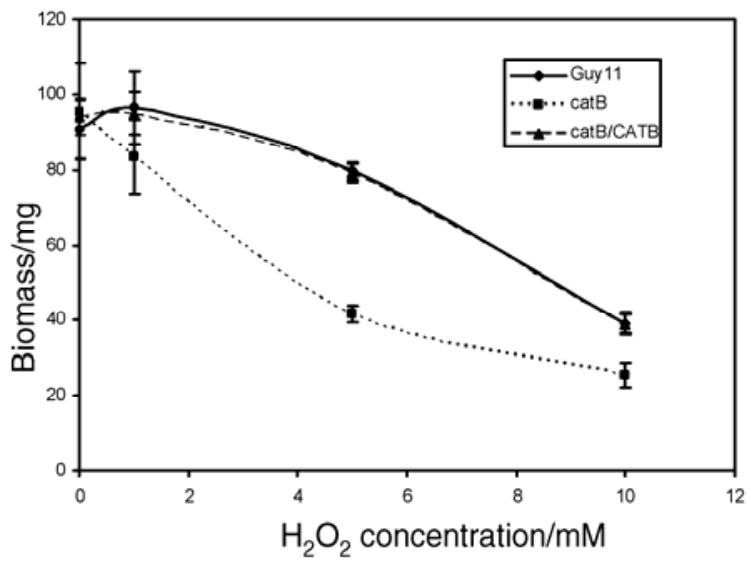

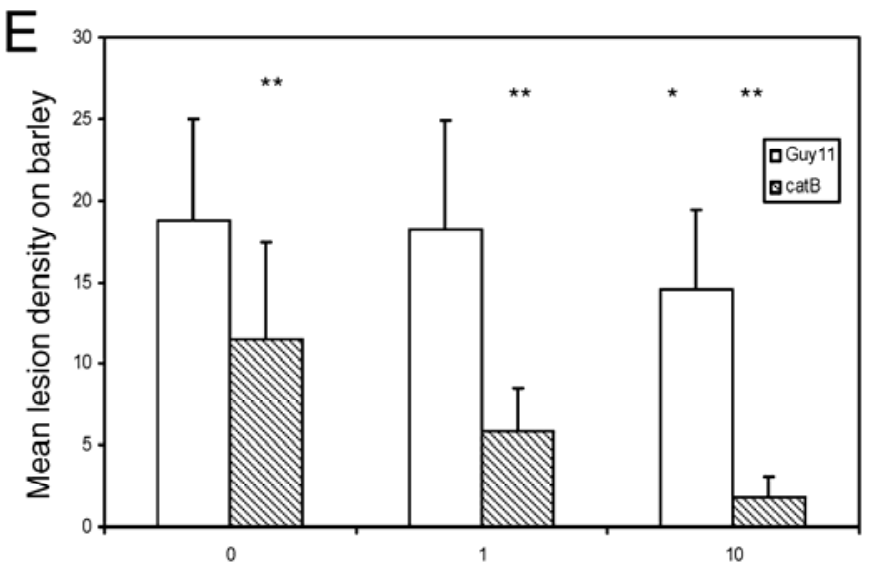

$\mathrm{H}_{2} \mathrm{O}_{2}$ concentration/mM treatment prior to infection

Fig. 5. Effect of exogenous $\mathrm{H}_{2} \mathrm{O}_{2}$ on Guy11, catB, and $c a t B / C A T B$ growth and virulence. A, Strains Guy 11 and catB differentiating on hydrophobic coverslips with and without $\mathrm{H}_{2} \mathrm{O}_{2}$ treatment $(0.1$ to $10 \mathrm{mM}), 10 \times 12$ germlings were scored at each timepoint. Error bars represent standard deviation from mean. $\mathbf{B}$ and $\mathbf{C}$, Effect of $\mathrm{H}_{2} \mathrm{O}_{2}(0$ to $20 \mathrm{mM})$ on agar plate growth of Guy11, catB, and catB/CATB at 10 days. Diameters were measured from three replicate experiments. D, Effect of $\mathrm{H}_{2} \mathrm{O}_{2}(0$ to $10 \mathrm{mM})$ on liquid culture growth of Guy11, catB, and catB/CATB. Biomass was recorded at 6 days postinoculation (dpi) with three replicates measured in two independent experiments. E, Effect of exogenously applied $\mathrm{H}_{2} \mathrm{O}_{2}(1$ and $10 \mathrm{mM}, 1-\mathrm{h}$ exposure on $1 \mathrm{ml}$ of $10^{4}$ spores) on the ability of Guy11 and catB strains to cause infection on barley plants. Mean disease lesion densities were counted at 6 dpi. Error bars indicate standard deviations. $P$ values were calculated comparing untreated with $\mathrm{H}_{2} \mathrm{O}_{2}$-treated $(1$ and $10 \mathrm{mM})$ spores individually for each strain. * indicates $P<0.05$, ** indicates $P<0.001$. All differences between Guy 11 and cat $B$ virulence after all $\mathrm{H}_{2} \mathrm{O}_{2}$ treatment were statistically significant differences at the 0.001 level. 
phenotype has not previously been recorded; for example, $B$. cinerea and Cochliobolus heterostrophus CATB-disrupted mutants were more sensitive to exogenous $\mathrm{H}_{2} \mathrm{O}_{2}$ than their wildtype counterparts (Robbertse et al. 2003; Schouten et al. 2002). Curiously, in the filamentous fungus $N$. crassa, inactivation of $C A T 3$ boosted production of conidia and aerial hyphae, leading to enhanced hyphal adhesion and to higher carotene levels (Michan et al. 2003). No such phenotypic changes were seen in the $M$. grisea catB mutant. Several of the catB mutant growth characteristics are, however, seen in the $M$. grisea metallothionein mutant, mmtl (Tucker et al. 2004). These include decreased sporulation, lighter pigmentation, resistance to $\mathrm{H}_{2} \mathrm{O}_{2}$ stress in vitro, and weakened fungal walls.

As endogenous oxidative stress is a major determinant of the rate of aging (Melov et al. 2000; Osiewacz 2002), we looked at the infection rates of differently aged $c a t B$ germlings. Deletion of $C A T B$ did not alter the number of disease lesions. This further supports the idea that the conidially-associated, predicted cytoplasmic CATA, rather than the putatively secreted CATB, is more likely involved in the management of endogenous oxidative stress.

The observation that the $c a t B$ mutant was able to develop normal-looking melanized appressoria in high concentrations of $\mathrm{H}_{2} \mathrm{O}_{2}$ while Guy11 was halted at the short germ-tube stage by this level of oxidative stress led us to compare infectivity of the two strains in vivo following exposure of ungerminated conidia to varying concentrations of exogenous $\mathrm{H}_{2} \mathrm{O}$. These plant infection assays revealed a dose-dependent loss of infectivity in $c a t B$, demonstrating a role for CATB in the management of host-produced $\mathrm{H}_{2} \mathrm{O}_{2}$. In the catB mutant, therefore, $\mathrm{H}_{2} \mathrm{O}_{2}$ affects the viability and proper functioning of appressoria but not their formation.

We asked whether CATB acts as a potent antioxidant that directly detoxifies the localized burst of plant $\mathrm{H}_{2} \mathrm{O}_{2}$ formed as the pathogen attempts penetration. This is an unlikely scenario, as deletion of $M$. grisea $C A T B$ did not affect scavenging of host-derived $\mathrm{H}_{2} \mathrm{O}_{2}$ by the fungus. Furthermore, the cat $B$ mutant tolerated and grew in concentrations of $\mathrm{H}_{2} \mathrm{O}_{2}$ that were toxic to Guy11. It appears more likely that CATB is involved in the formation or the maintenance of a robust fungal cell wall. The evidence in support of this model are the following mutant phenotypes: i) reduced conidiogenesis, ii) conidia more prone to collapse on exposure to hyperosmotic stress, iii) greater sensitivity to protoplasting enzymes, and iv) appressoria more prone to cytorrhysis, i.e., the mutant cannot accumulate high concentrations of glycerol prior to penetration peg emergence. This body of data suggests that the large subunit catalase $\mathrm{B}$ in $M$. grisea is involved in cell-wall reinforcement during conidiogenesis and, more importantly, during appressorium maturation at the time of host penetration.

However, CATB is unlikely to be involved in wall turnover, as we showed that inhibitors and wall modifiers of chitin and glucan synthesis do not differentially affect growth of the $c a t B$ mutant or Guy11. An insight into the variation in wall composition of the two strains is demonstrated by the Raman spectroscopic data, which indicated that the catB mutant cell walls are likely to be in a hyperoxidant state. This implies a 'blockage,' perhaps in either or both the formation or oxidative cross-linking of DHN melanin in M. grisea (Caesar-Tonthat et al. 1995; Henson et al. 1999). We observed that the activity of the secreted blue copper oxidase, laccase, was reduced in $c a t B$ compared with that in Guy11 and pursued this by considering the effect of copper sulphate, known to stimulate the biosynthesis of melanin by inducing laccase activity, on colony growth (Galhaup and Haltrich 2001; Parisot et al. 2002). The catB mutant tolerated higher concentrations of copper than did Guy11. Addition of copper sulphate led to restoration of laccase activity and to darker colony pigmentation in $c a t B$ mutant. Taken collectively, these data imply that the $c a t B$ mutant is in a hyperoxidant state, which may, in turn, lead to reduced oxidative cross-linking of melanin. This can be compensated for by a boost in laccase activity in the mutant (as effected by exogenous copper). Surprisingly, the
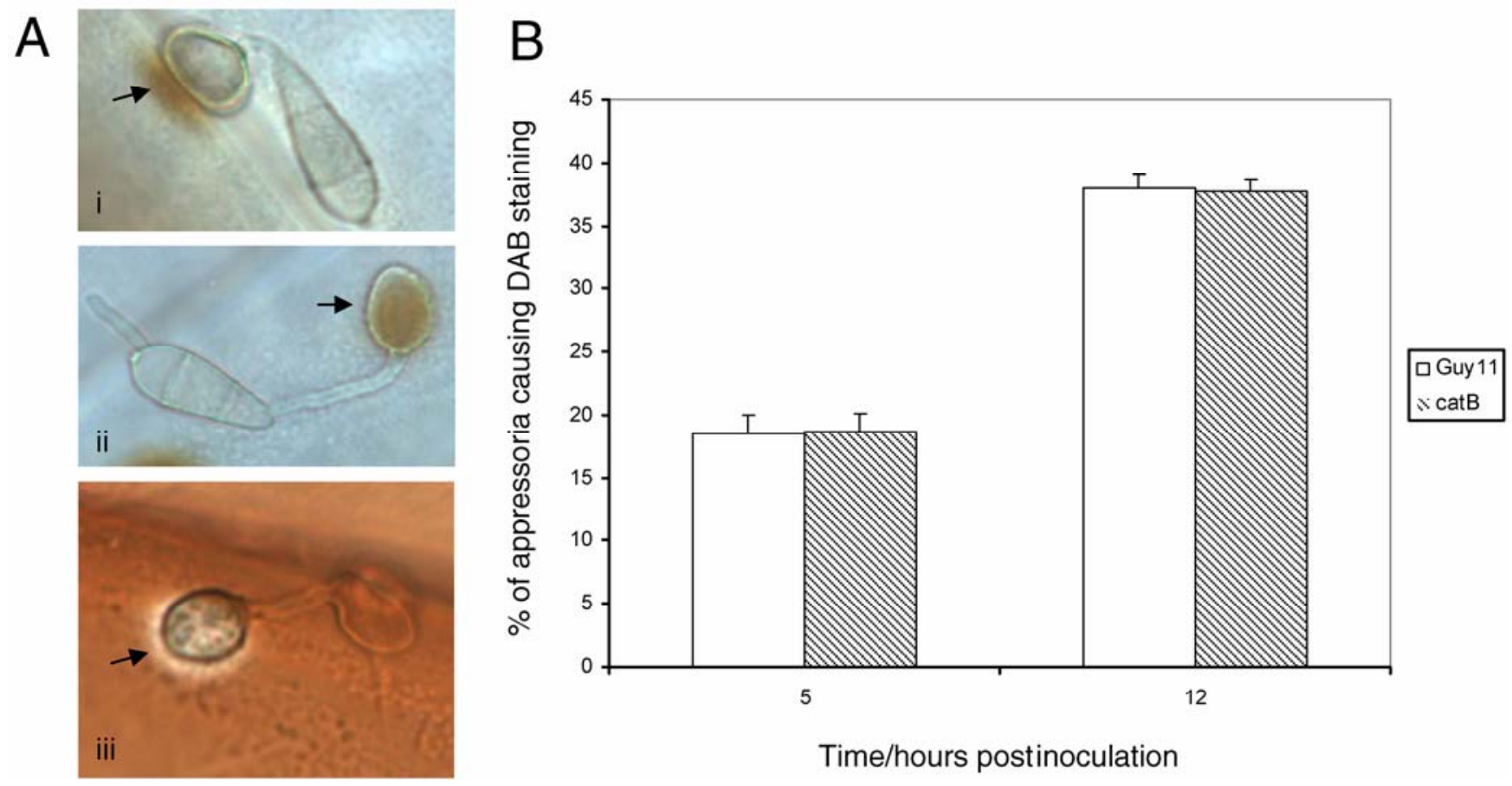

Fig. 6. Evidence for the host oxidative burst in barley. Ai and ii. DAB (3,3'-diaminobenzidine) staining reveals a burst of $\mathrm{H}_{2} \mathrm{O}_{2}$ in barley cv. Pastoral beneath Guy11 appressoria (arrow) from $4 \mathrm{~h}$ postinoculation (hpi). iii, DAB- $\mathrm{H}_{2} \mathrm{O}_{2}$ staining reveals clearing of $\mathrm{H}_{2} \mathrm{O}_{2}$ beneath the appressorium (arrow) at 12 hpi. B, Presence of DAB staining in epidermal cells beneath Guy11 and catB germlings at 5 and 12 hpi. Each timepoint represents $12 \times 10$ spores scored in two independent experiments. Error bars represent standard deviations from the mean. 
melanin biosynthesis inhibitor TCZ, considered to interfere with DHN biosynthesis before the oxidative cross-linking of melanin occurs (Kurahashi 2001), suppressed colony growth more effectively in the catB mutant than in Guy11. Other melanin-deficient mutants in $M$. grisea also failed to generate sufficient turgor to cause disease (Howard et al. 1991), but unlike catB and $m m t 1$ mutants, these mutants are more sensitive to ROS than the wildtype strain (Pasechnik et al. 1998).

The fact that the cat $B$ mutant is severely impaired in virulence but does not show complete loss of pathogenicity suggests that there are additional antioxidant enzymes that critically contrib- ute to defense from oxidative injury imposed by the host. For example, glutathione peroxidases and peroxideroxins have been demonstrated to neutralize exogenous $\mathrm{H}_{2} \mathrm{O}_{2}$ and might also take part in ROS-dependent signaling cascades (Aguirre et al. 2005; Torres et al. 2005). The interplay of such proteins is likely to form an extensive antioxidant network in M. grisea during the establishment of rice blast disease; much remains to be unmasked.

Taken together, these data suggest that CATB is involved in the melanization and, thus, in the fortification of the fungal cell wall. This role is of particular importance for the genera-
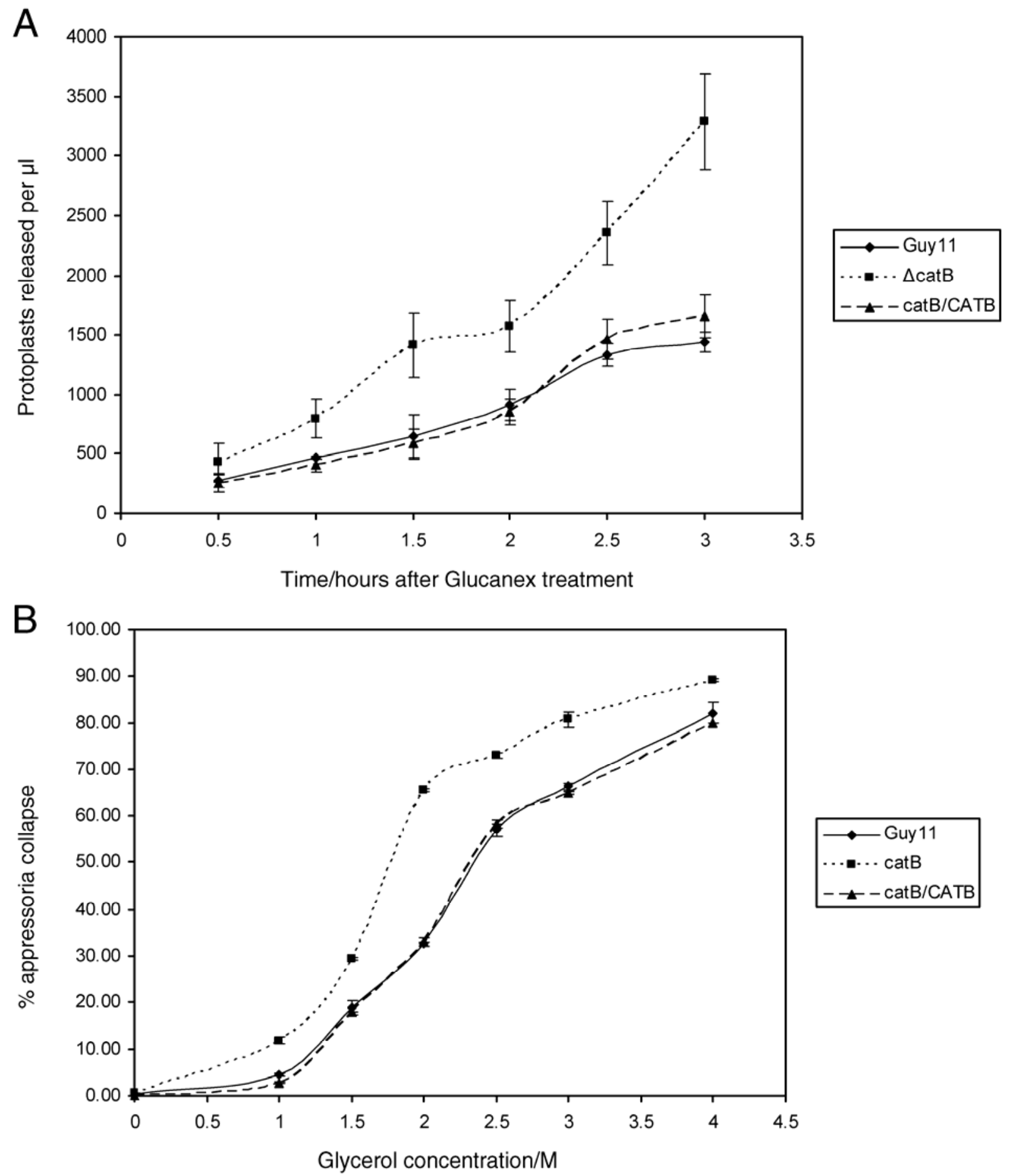

Fig. 7. The $c a t B$ mutant has weakened cell walls. A, Release of protoplasts from Guy11, cat $B$, and $c a t B / C A T B$ mycelium treated with cell-wall-degrading enzyme Glucanex. Error bars represent the standard deviation of the means. B, Effect of 10-min exposure of 24-h Guy11, catB, and catB/CATB appressoriumstage germlings to 0 to $4 \mathrm{M}$ glycerol. A total of 300 appressoria were scored to assess collapse in two independently conducted experiments. 
tion of sufficient turgor pressure to enable the penetration peg to pass through the cuticle and breach the plant cell wall. It is unlikely, however, that CATB is involved in detoxification of the host oxidative burst response. The data attests to an important and novel developmental role for CATB in the infection process. We seek now to uncover how CATB influences the oxidative cross-linking of the fungal cell wall.

\section{MATERIALS AND METHODS}

Fungal strains, growth conditions, and nucleic acid analyses. M. grisea wild-type rice-pathogenic strain Guy11 was used throughout this work; strain TH3 was used in the sexual crosses.

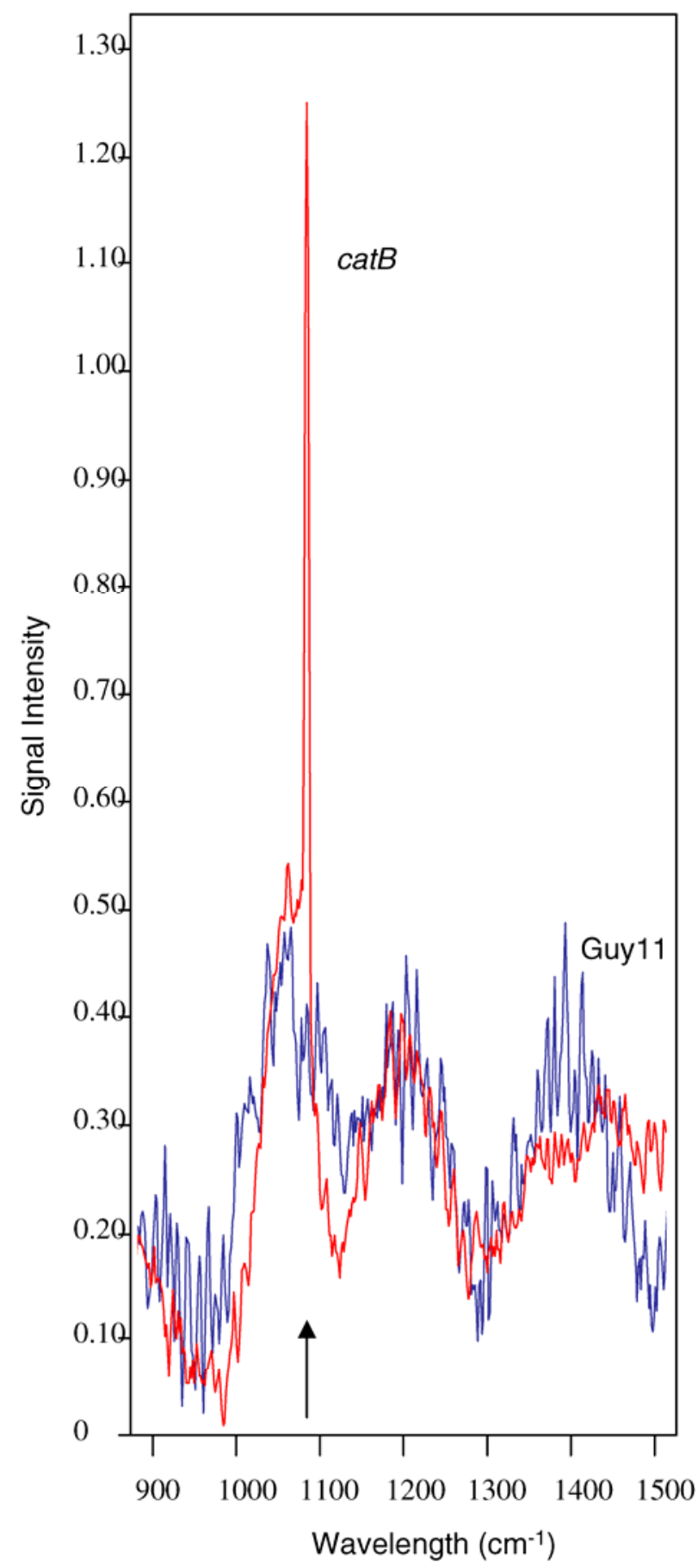

Fig. 8. Raman spectroscopy data of Guy 11 and $c a t B$ cell walls. The clear peak at wavelength $1,085 \mathrm{~cm}^{-1}$ indicates the prevalence of $\mathrm{C}-\mathrm{O}$ groups in the $c a t B$ wall.
Strain maintenance, composition of media, DNA and RNA extraction, and transformation protocols were as described by Talbot and associates (1993). Standard procedures were adopted for restriction-enzyme digestion, gel electrophoresis, gel blots, and sequencing (Sambrook and Russell 2001).

Monitoring gene-expression levels by qrtRT-PCR profiling.

We used barley as the host for two reasons: i) we were able to routinely peel off inoculated adaxial barley epidermal strips and so reduce the plant component in RNA preps, but rice epidermal peels proved problematic, and ii) these tissues were amenable to appressorium-mediated penetration assays. Production of good-quality rice epidermal peels proved more problematic. Considerable care was taken to monitor the timing of stage-specific germling development on barley, so as to synchronize maturation of appressoria and subsequent penetration events. Stage-specific material was collected from wildtype strain Guy 11 or catB mutant at $0,5,12$, and 20 hpi of detached barley leaves, for RNA extraction. The abaxial epider-
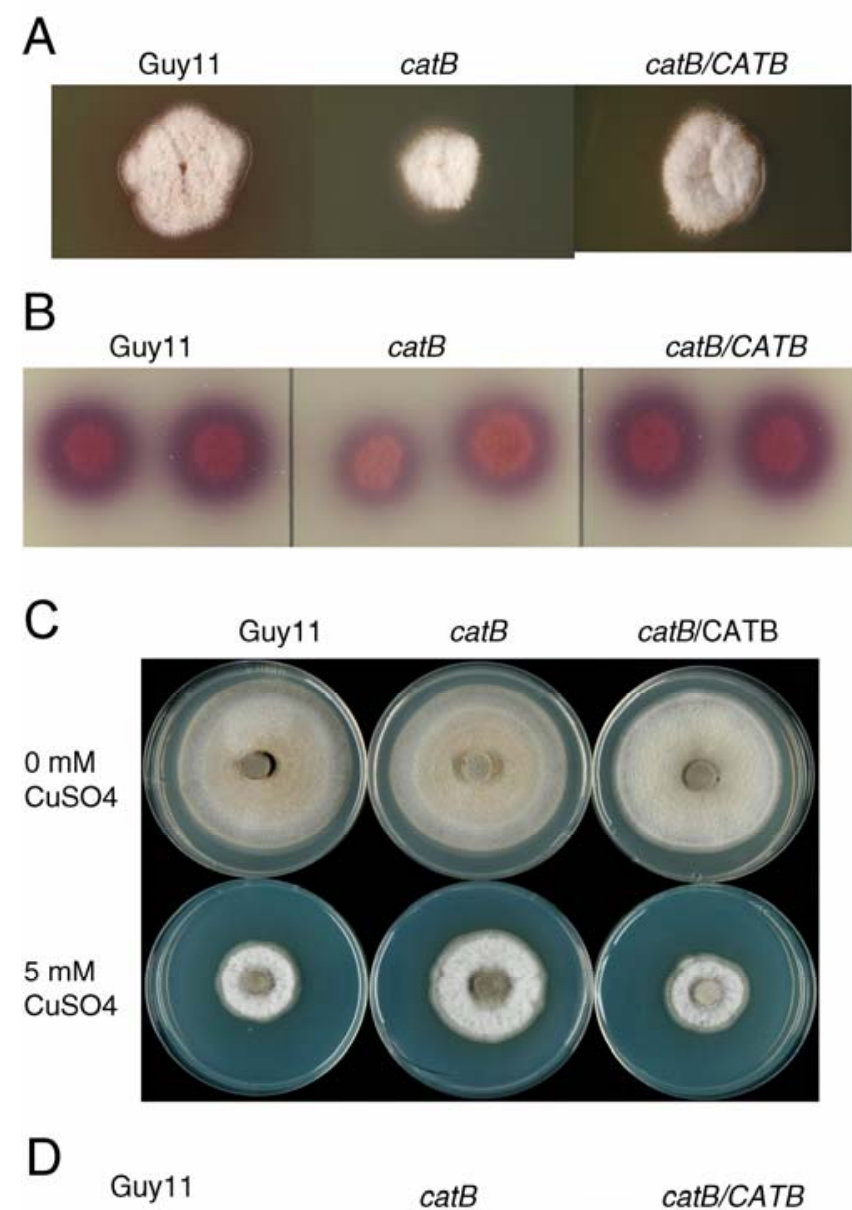

catB

catB/CATB

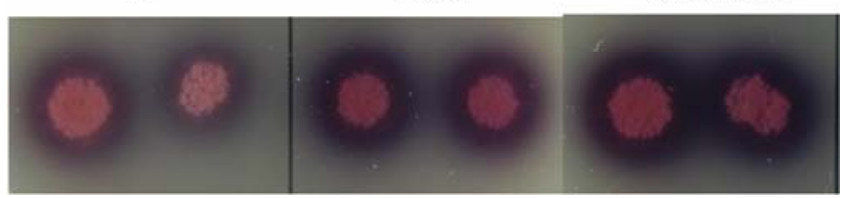

Fig. 9. The $c a t B$ mutant has compromised melanization. A, Sensitivity of Guy $11, c a t B$, and $c a t B / C A T B$ colonies to exposure to the fungicide Tricyclazole at the rate of $100 \mu \mathrm{g} \mathrm{ml}^{-1}$. B, Laccase activity monitored in 0.2 $\mathrm{mM} 2$ '-azino-di-3-ethylbenzathiazoline-6-sulfonate at 5 days postinoculation of equivalent numbers of Guy11, catB, and $c a t B / C A T B$ conidia. $\mathbf{C}$, Sensitivity of Guy $11, c a t B$, and $c a t B / C A T B$ colonies to exposure to $5 \mathrm{mM}$ copper sulphate. D, Laccase activity of Guy11, catB mutant, and $c a t B / C A T B$ in the presence of $5 \mathrm{mM}$ copper sulphate. 
mal surface was removed. First-strand cDNA was synthesized from total RNA using the RETROscript first strand synthesis kit (Ambion, Austin, TX, U.S.A.). Real-time PCR was performed on first-strand cDNAs, prepared as above, using Qiagen QuantiTect SYBR green RT-PCR kit (Qiagen Ltd., Hybaid, Cambridge). Primers were designed to amplify approximately $100 \mathrm{bp}$ and to bridge introns of CATA (accession number MG100061), CATB (MG06442), CPXA (MG04337), $C P X B$ (MG09834), and $C C P B$ (MG04545). Transcript abundance of the target genes relative to the constitutively expressed normalizer $\beta$-TUB gene (MG06604) was quantified, taking account of primer efficiencies as described by Pfaffl (2001). A second constitutive control gene, elongation factor 1 (EGF1) (MG03641) was also used as an independent normalizer. Expression analysis of $C A T B$ and $C A T A$ in in vitro-grown Guy11 was with mycelium harvested from liquid cultures exposed to 1 to $5 \mathrm{mM} \mathrm{H} \mathrm{H}_{2} \mathrm{O}_{2}$ for up to $3 \mathrm{~h}$. The forward $(\mathrm{F})$ and reverse $(\mathrm{R})$ primers were as follows.

$\beta T U B$ : F: 5' CTCTGCCATCTTCCGTGGA $3^{\prime}$ and

R: 5' ACGAAGTACGACGAGTTCTTGTTCT 3'

CATA: F: 5' GGTGGACGCCGTGTACGT $3^{\prime}$ and

R: 5' CCGTTCTTGGACAATGTCTTGA 3'

$C A T B$ : F: 5' GGTCACCGTCCACAACAATAATC $3^{\prime}$ and

R: 5' TCAGGGCACTGGGTGTATAAGG 3'

CPXA: F: 5' TTGCTCCTTCCAAGCTTATCCA $3^{\prime}$ and

R: 5' CTTGTCACCTCCACGGAATGT 3'

CPXB: F: 5' CGTGGCGGTGGTGGAAT $3^{\prime}$ and R: 5' TGATGGGCCAAATCAGCC 3'

$C C P B$ : F: 5' GGGATGGTCCTAAGCAGTACGTC 3' and

R: 5' TGTCCTCGATGAGGCACATG 3'

EGF1: F: 5' CCTTGTACCAAGGAGCGTTAGG 3' and

\section{R: 5' TCAACGGTGACCACATGATCTC 3'}

Real-time quantification was performed using the ABI Prism 7300 sequence detection systems (Applied Biosystems, Foster City, CA, U.S.A.), cycling $50^{\circ} \mathrm{C}, 2$ min for 1 cycle, $95^{\circ} \mathrm{C}, 10$ min for 1 cycle, $95^{\circ} \mathrm{C}, 15 \mathrm{~s}$ and $60^{\circ} \mathrm{C} 1 \mathrm{~min}$ for 40 cycles. No template controls were monitored for the presence of primer dimers, and no-reverse-transcriptase controls were included for each cDNA sample. PCR were carried out in triplicate and mean values were determined.

Targeted gene replacement and complementation of $C A T B$.

The full-length $C A T B$ gene and its $1.1-\mathrm{kb}$ upstream and $0.9-\mathrm{kb}$ downstream flanking sequences were amplified by PCR and were cloned into the EcoRI site of pT7Blue vector (Novagen, Inc., Madison, WI, U.S.A.) to form plasmid pZZ100. Partial digestion of pZZ100 with SalI released the $C A T B$ gene sequence, which was replaced by the SalI-hygromycin B resistance gene $(1.4 \mathrm{~kb})$ released from plasmid pCB1636 (Sweigard 1997), forming the $C A T B$-replacement plasmid pZZ101. Protoplast-mediated transformation of $M$. grisea Guy11 was carried out following the method of Talbot and associates (1993). To confirm CATB replacement, NdeIdigested genomic DNA from hygromycin-resistant catB transformants was gel blotted and hybridized with a 1,946-bp fragment from the Guy11 CATB gene, which was $\alpha^{32} \mathrm{P}$ dCTP radiolabeled with the Prime-It II random primer labeling kit (Stratagene, La Jolla, CA, U.S.A.). To assess whether a single integration event had occurred, Guy11 and catB mutant were digested with HindIII, were gel blotted, and were hybridized to the 1.4-kb hygromycin B gene amplified from pCB1632. For complementation of the $c a t B$ mutant, a 4,943bp KpnI-SpeI fragment spanning the $C A T B$ locus was excised from pZZ101 and was ligated into KpnI-SpeI-digested pCB1532, which carries the sulphonylurea resistance selectable marker (Carroll et al. 1994). The resulting plasmid pPS300 was sequence-verified and reintroduced into the catB mutant, with transformants selected on $100 \mu \mathrm{g} \mathrm{ml} \mathrm{m}^{-1}$ chlorimuron ethyl; the complemented strain was designated $c a t B / \mathrm{CATB}$. To ensure that single integration of $C A T B$ into $c a t B$ had occurred, HindIII-digested Guy11 and $c a t B$ DNA was subjected to Southern blot analysis and was hybridized with a 5.7-kb HindIII fragment carrying the $C A T B$ sequence.

\section{Plant infection and infection-related germling development assays.}

Plant infection assays were performed on blast-susceptible 14-day-old seedlings of rice (Oryza sativa) cultivar CO-39 or 7-day-old seedlings of barley (Hordeum vulgare) cultivar Pastoral. A suspension of $10^{4}$ conidia per milliliter in $0.25 \%$ (vol/vol) gelatin water was applied, using an artist's airbrush with high-pressure air from a Kenair duster (Kenro Ltd., Wiltshire, U.K.) as described in Talbot and associates (1993). Disease lesions were counted from 40 randomly chosen $5-\mathrm{cm}$ leaf tips, as detailed in Valent and associates (1991), in three independent experiments. Mean disease-lesion densities were calculated and compared.

\section{Phenotypic analyses of catB mutant.}

Vegetative growth of Guy11 and $c a t B$ mutant was monitored using conidia harvested from 12-day cultures adjusted to $10^{4}$ spores per milliliter or by plug inoculum. Exposure to exogenous 0.75 to $20 \mathrm{mM} \mathrm{H} \mathrm{O}_{2}, 0.0001$ to $0.05 \%$ (wt/vol) SDS, 0.01 to $5 \mathrm{mM}$ copper sulphate, nikkomycin Z (Sigma, St. Louis) , polyoxin D (Calbiochem, San Diego, CA, U.S.A.), caspofungin (Merck Sharp, Amsterdam) at rates up to $100 \mu \mathrm{g} \mathrm{ml}^{-1}$, Calcofluor White (Sigma) at rates up to 2.5 $\mathrm{mg} \mathrm{ml}{ }^{-1}$, or fungicide TCZ, 5-methyl-1,2,4 triazole(3.4-6) benzothiazole (a gift from A. Corran, Syngenta, Jealott's Hill, Berkshire, U.K.) at rates up to 1 to $150 \mu \mathrm{g} \mathrm{ml}^{-1}$ was assessed by measuring colony diameter at $10 \mathrm{dpi}$. Biomass was recorded in shake flask cultures $(150 \mathrm{rpm})$ grown for $48 \mathrm{~h}$ at $250^{\circ} \mathrm{C}$, whereupon $0,1,5$, and $10 \mathrm{mM} \mathrm{H} \mathrm{H}_{2}$ was added and cultures were grown for a further $24 \mathrm{~h}$. Fungal biomass was recorded by dry weight determination of three replicates per treatment in two independent experiments. Laccase activity was monitored on $0.2 \mathrm{mM}$ ABTS agar plate assays of mycelial plugs at 2 dpi.

Infection-related appressorium development was assessed by following germling differentiation and appressorium formation on hydrophobic plastic coverslips up to $24 \mathrm{hpi}$, by light microscopy. Germling exposure to $0,0.1$, 1, and $10 \mathrm{mM} \mathrm{H}_{2} \mathrm{O}_{2}$ on hydrophobic coverslips was scored for effects on germination and development.

Sensitivity to the protoplasting enzyme $\beta$-1,3-glucanase, Glucanex (Sigma) was assayed by incubating 48-h grown mycelium in $12.5 \mathrm{mg}$ Glucanex per milliliter in OM buffer $(1.2 \mathrm{M}$ $\mathrm{MgSO}_{4}, 10 \mathrm{mM} \mathrm{Na} \mathrm{HPO}_{4} / \mathrm{NaH}_{2} \mathrm{PO}_{4}, \mathrm{pH} 5.8$ ) for $3 \mathrm{~h}$ at $30^{\circ} \mathrm{C}$. At 30-min intervals, protoplasts were withdrawn and counted by hemocytometry.

Conidial collapse was observed following exposure of conidia to 1 to $3 \mathrm{M}$ glycerol for $10 \mathrm{~min}$. Appressorium turgor was assessed by a cell-collapse assay (Dixon et al. 1999); germlings differentiating in water droplets on hydrophobic coverslips were left for $24 \mathrm{~h}$ under high humidity conditions. The water was replaced by 0 to $4 \mathrm{M}$ glycerol, germlings were left for $10 \mathrm{~min}$, and 300 appressoria per treatment were scored for cell collapse, in two independent experiments.

Perithecia and ascospore formation was followed by crossing the catB mutant (Guy 11 background) with opposite mating type strain TH3. Plug inoculum of the two strains were placed $4 \mathrm{~cm}$ apart on oatmeal agar and were incubated under constant fluorescent light at $18^{\circ} \mathrm{C}$ for 28 days. Perithecia were gently crushed to reveal asci and ascospores. 
The host oxidative burst and staining for $\mathrm{H}_{2} \mathrm{O}_{2}$ scavenger activity.

DAB staining of host tissues was with leaves placed in $1 \mathrm{mg}$ of 3,3'-diaminobenzidine tetrahydrochloride per milliliter and incubated for $8 \mathrm{~h}$ at room temperature. At specific timepoints up to $24 \mathrm{hpi}$, leaves were placed in a clearing solution of ethanol/acetic acid (vol/vol) and, then, mounted in $30 \%$ glycerol and $30 \%$ lactic acid, and were examined for DAB staining by light microscopy. The percentage of germlings showing DAB staining of the underlying host tissues were recorded by scoring 10 germlings on each of 12 leaves in two independent experiments.

Staining for Guy11 and catB mutant $\mathrm{H}_{2} \mathrm{O}_{2}$ scavenger activity was with abaxial epidermis barley leaf peels, at specific timepoints postinoculation, clamped between the jaws of hairgrips, and then, immersed in staining solution $\left(1 \mathrm{mM} \mathrm{H} \mathrm{H}_{2}, 2.5 \mathrm{mM}\right.$ $\mathrm{DAB}, 0.1 \%$ Triton $\mathrm{X} 100)$ for $1 \mathrm{~h}$ at room temperature, rinsed twice in distilled water, and mounted in $30 \%$ glycerol. The percentage of appressoria overlying $\mathrm{H}_{2} \mathrm{O}_{2}$ clearing was recorded.

\section{SEM and Raman microscopy.}

Scanning electron microscopy (SEM). Small squares of sporulating mycelia on agar were mounted on copper stubs at room temperature using Leit $\mathrm{C}$ carbon conductive cement. The stubs were rapidly inserted under a stream of dry argon into precooled stub holders (at $-186^{\circ} \mathrm{C}$ ) withdrawn from the SP2000A sputter-cryo system. The sample was introduced to the cold stage of the JEOL JSM840A scanning electron microscope at about $-150^{\circ} \mathrm{C}$ to inspect for frost. As no serious frosting was observed, they were returned to the sputter-cryo system and, after recooling to $-186^{\circ} \mathrm{C}$, were coated with gold and palladium under argon. The samples were returned to the microscope and digital images were acquired using SemAfore.

Raman microscopy. Raman microscopy was performed using a LabRAM 300 microscope (Jobin-Yvon Ltd., Stanmore, Middlesex, U.K.). Scattering was excited by a frequency-doubled 532-nm Nd:YAG laser. Ten-day-old plate cultures of $M$. grisea catB mutant and Guy11 strains were harvested and filtered through two layers of Miracloth, were ground with pestle and mortar to a fine powder in $20 \mathrm{mM}$ Tris, $50 \mathrm{mM}$ EDTA, $\mathrm{pH} 8$, in liquid nitrogen, were centrifuged at $3,000 \times g$ for $10 \mathrm{~min}$, and were lyophilized. A $10-\mu$ l sample was spread on a quartz slide and was targeted by confocal optics. Spectra were acquired between 544 and $1,972 \mathrm{~cm}^{-1}$ at approximately 5 to $8 \mathrm{~mW}$ for 60 to $90 \mathrm{~s}$ for three samples of each preparation, were baseline corrected and normalized by Labspec software (JobinYvon Ltd.), and were imported into MVSP 3.12d (Kovach Computing, Pentraeth, Anglesey, U.K.) and MatlabR12 (Maths Works, Natick, MA, U.S.A.) for multivariate analysis.

\section{ACKNOWLEDGMENTS}

We are grateful to A. Spiers (Plant Sciences, Oxford) and W. Huang (Centre for Ecology and Hydrology, Oxford) for their input to the Raman spectroscopy, to B. Thomas and T. Carver (Institute of Grassland and Environmental Research, Aberystwyth) for their help with the SEM images, N. Talbot (Exeter) for strain TH3 and for his constant encouragement, and to G. Preston and M. Illes (Plant Sciences) for useful discussions. This work was supported by grants to S. J. Gurr from the Biotechnology and Biological Sciences Research Council (P18303) and a Cooperative Award in Science and Engineering studentship (with Syngenta) for C. Henderson.

\section{LITERATURE CITATIONS}

Aguirre, J., Rios-Momberg, M., Hewitt, D., and Hansberg, W. 2005. Reactive oxygen species and development in microbial eukaryotes. Trends Microbiol. 13:111-118.

Bourett, T. M., and Howard, R. J. 1990. In vitro development of penetration structures in the rice blast fungus Magnaporthe-Grisea. Can. J. Bot. 68:329-342.
Cabib, E. 1991. Differential inhibition of chitin synthetases 1 and 2 from Saccharomyces cerevisiae by polyoxin D and nikkomycins. Antimicrob. Agents Ch. 35:170-173.

Caesar-Tonthat, T., Van Ommen, K. F., Geesey, G. G., and Henson, J. M. 1995. Melanin production by a filamentous soil fungus in response to copper and localization of copper sulfide by sulfide-silver staining. Appl. Environ. Microbiol. 61:1968-1975.

Calera, J. A., Paris, S., Monod, M., Hamilton, A. J., Debeaupuis, J. P., Diaquin, M., Lopez-Medrano, R., Leal, F., and Latge, J. P. 1997. Cloning and disruption of the antigenic catalase gene of Aspergillus fumigatus. Infect. Immun. 65:4718-4724.

Carroll, A. M., Sweigard, J. A., and Valent, B. 1994. Improved vectors for selecting resistance to hygromycin. Fungal Genet. Newsl. 41:22.

de Jong, J. C., McCormack, B. J., Smirnoff, N., and Talbot, N. J. 1997. Glycerol generates turgor in rice blast. Nature 389:244.

Dean, R. A., Talbot, N. J., Ebbole, D. J., Farman, M. L., Mitchell, T. K., Orbach, M. J., Thon, M., Kulkarni, R., Xu, J. R., Pan, H., Read, N. D., Lee, Y. H., Carbone, I., Brown, D., Oh, Y. Y., Donofrio, N., Jeong, J. S., Soanes, D. M., Djonovic, S., Kolomiets, E., Rehmeyer, C., Li, W., Harding, M., Kim, S., Lebrun, M. H., Bohnert, H., Coughlan, S., Butler, J., Calvo, S., Ma, L. J., Nicol, R., Purcell, S., Nusbaum, C., Galagan, J. E., and Birren, B. W. 2005. The genome sequence of the rice blast fungus Magnaporthe grisea. Nature 434:980-986.

Debono, M., and Gordee, R. S. 1994. Antibiotics That inhibit fungal cellwall development. Ann. Rev.Microbiol. 48:471-497.

Dixon, K. P., Xu, J. R., Smirnoff, N., and Talbot, N. J. 1999. Independent signaling pathways regulate cellular turgor during hyperosmotic stress and appressorium-mediated plant infection by Magnaporthe grisea. Plant Cell 11:2045-2058.

Galhaup, C., and Haltrich, D. 2001. Enhanced formation of laccase activity by the white-rot fungus Trametes pubescens in the presence of copper. Appl. Microbiol. Biotechnol. 56:225-232.

Garre, V., Muller, U., and Tudzynski, P. 1998. Cloning, characterization, and targeted disruption of cpcat1, coding for an in planta secreted catalase of Claviceps purpurea. Mol Plant-Microbe Interact 11:772-783.

Giles, S. S., Stajich, J. E., Nichols, C., Gerrald, Q. D., Alspaugh, J. A., Dietrich, F., and Perfect, J. R. 2006. The Cryptococcus neoformans catalase gene family and its role in antioxidant defense. Eukaryot. Cell 5:1447-1459.

Henson, J. M., Butler, M. J., and Day, A. W. 1999. The dark side of the mycelium: Melanins of phytopathogenic fungi. Ann. Rev. Phytopathol. 37:447-471.

Howard, R. J., and Valent, B. 1996. Breaking and entering: Host penetration by the fungal rice blast pathogen Magnaporthe grisea. Ann. Rev. Microbiol. 50:491-512.

Howard, R. J., Ferrari, M. A., Roach, D. H., and Money, N. P. 1991. Penetration of hard substrates by a fungus employing enormous turgor pressures. Proc. Natl. Acad. Sci. U. S. A. 88:11281-11284.

Johnson, C. H., Klotz, M. G., York, J. L., Kruft, V., and McEwen, J. E. 2002. Redundancy, phylogeny and differential expression of Histoplasma capsulatum catalases. Microbiology 148:1129-1142.

Kawasaki, L., and Aguirre, J. 2001. Multiple catalase genes are differentially regulated in Aspergillus nidulans. J. Bacteriol. 183:1434-1440.

Kurahashi, Y. 2001. Melanin biosynthesis inhibitors MBIs for control of rice blast. Pestic. Outlook 12:32-35.

Kurtz, M. B., Abruzzo, G., Bartizal, K., Marrinan, J. A., Li, W., Milligan, J., Nollstadt, K., and Douglas, C. M. 1996. Characterization of echinocardin-resistant mutants of Candida albicans: Genetic, biochemical, and virulence studies. Infect. Immun. 64:3244-3251.

Lamb, C., and Dixon, R. A. 1997. The oxidative burst in plant disease resistance. Annu. Rev. Plant Physiol. Plant Mol. Biol. 48:251-275.

Lledias, F., Rangel, P., and Hansberg, W. 1999. Singlet oxygen is part of a hyperoxidant state generated during spore germination. Free Radic. Biol. Med. 26:1396-1404.

Maquelin, K., Choo-Smith, L. P., Endtz, H. P., Bruining, H. A., and Puppels, G. J. 2002. Rapid identification of Candida species by confocal Raman micro spectroscopy. J. Clin. Microbiol. 40:594-600.

Mellersh, D. G., Foulds, I. V., Higgins, V. J., and Heath, M. C. 2002. $\mathrm{H}_{2} \mathrm{O}_{2}$ plays different roles in determining penetration failure in three diverse plant-fungal interactions. Plant J. 29:257-268.

Melov, S., Ravenscroft, J., Malik, S., Gill, M. S., Walker, D. W., Clayton, P. E., Wallace, D. C., Malfroy, B., Doctrow, S. R., and Lithgow, G. J. 2000. Extension of life-span with superoxide dismutase/catalase mimetics. Science 289:1567-1569.

Michan, S., Lledias, F., Baldwin, J. D., Natvig, D. O., and Hansberg, W. 2002. Regulation and oxidation of two large monofunctional catalases. Free Radic. Biol. Med. 33:521-532.

Michan, S., Lledias, F., and Hansberg, W. 2003. Asexual development is increased in Neurospora crassa cat-3-null mutant strains. Eukaryot. Cell 2:798-808. 
Money, N. P., and Howard, R. J. 1996. Confirmation of a link between fungal pigmentation, turgor pressure, and pathogenicity using a new method of turgor measurement. Fungal Genet. Biol. 20:217-227.

Nakagawa, Y., Kanbe, T., and Mizuguchi, I. 2003. Disruption of the human pathogenic yeast Candida albicans catalase gene decreases survival in mouse-model infection and elevates susceptibility to higher temperature and to detergents. Microbiol Immunol 47:395-403.

Nathues, E., Joshi, S., Tenberge, K. B., von den Driesch, M., Oeser, B., Baumer, N., Mihlan, M., and Tudzynski, P. 2004. CPTF1, a CREB-like transcription factor, is involved in the oxidative stress response in the phytopathogen Claviceps purpurea and modulates ROS level in its host Secale cereale. Mol. Plant-Microbe Interact. 17:383-393.

Navarro, R. E., Stringer, M. A., Hansberg, W., Timberlake, W. E., and Aguirre, J. 1996. catA, a new Aspergillus nidulans gene encoding a developmentally regulated catalase. Curr. Genet. 29:352-359.

Osiewacz, H. D. 2002. Genes, mitochondria and aging in filamentous fungi. Aging Res. Rev. 1:425-442.

Paris, S., Wysong, D., Debeaupuis, J. P., Shibuya, K., Philippe, B., Diamond, R. D., and Latge, J. P. 2003. Catalases of Aspergillus fumigatus. Infect. Immun. 71:3551-3562.

Parisot, D., Dufresne, M., Veneault, C., Lauge, R., and Langin, T. 2002. clap1, a gene encoding a copper-transporting ATPase involved in the process of infection by the phytopathogenic fungus Colletotrichum lindemuthianum. Mol. Gene. Genomics 268:139-151.

Pasechnik, T. D., Aver'yanov, A. A., Lapikova, V. P., Kovalenko, E. D., and Kolomietz, T. M. 1998. The involvement of activated oxygen in the expression of the vertical and horizontal resistance of rice to blast disease. Russ. J. Plant Physiol. 45:371-378.

Peraza, L., and Hansberg, W. 2002. Neurospora crassa catalases, singlet oxygen and cell differentiation. Biol. Chem. 383:569-575.

Pfaffl, M. W. 2001. A new mathematical model for relative quantification in real-time RT-PCR. Nucleic Acids Res. 29:e45.

Robbertse, B., Yoder, O. C., Nguyen, A., Schoch, C. L., and Turgeon, B. G. 2003. Deletion of all Cochliobolus heterostrophus monofunctional catalase-encoding genes reveals a role for one in sensitivity to oxidative stress but none with a role in virulence. Mol. Plant-Microbe Interact. 16:1013-1021.

Sambrook, J., and Russell, D.W. 2001. Molecular Cloning: A Laboratory Manual. Cold Spring Laboratory Press, Cold Springs Harbor, NY, U.S.A.

Schouten, A., Tenberge, K. B., Vermeer, J., Stewart, J., Wagemakers, L.,
Williamson, B., and Van Kan, J. A. L. 2002. Functional analysis of an extracellular catalase of Botrytis cinerea. Mol. Plant Pathol. 3:227-238.

Sweigard, J. 1997. A series of vectors for fungal transformation. Fungal Genet. Newsl. 44:52-53.

Talbot, N. J., Ebbole, D. J., and Hamer, J. E. 1993. Identification and characterization of $M P G 1$, a gene involved in pathogenicity from the rice blast fungus Magnaporthe grisea. Plant Cell 5:1575-1590.

Talbot, N. J. 2003. On the trail of a cereal killer: Exploring the biology of Magnaporthe grisea. Annu. Rev. Microbiol. 57:177-202.

Thompson, J. E., Fahnestock, S., Farrall, L., Liao, D. I., Valent, B., and Jordan, D. B. 2000. The second naphthol reductase of fungal melanin biosynthesis in Magnaporthe grisea-tetrahydroxynaphthalene reductase. J. Biol. Chem. 275:34867-34872.

Torres, M. A., Jones, J. D., and Dangl, J. L. 2005. Pathogen-induced, NADPH oxidase-derived reactive oxygen intermediates suppress spread of cell death in Arabidopsis thaliana. Nat. Genet. 37:1130-1134.

Torres, M. A., Jones, J. D. G., and Dangl, J. L. 2006. Reactive oxygen species signaling in response to pathogens. Plant Physiol. 141:373-378.

Tucker, S. L., and Talbot, N. J . 2001. Surface attachment and pre-penetration stage development by plant pathogenic fungi. Ann. Rev. Phytopathol. 39:385-417.

Tucker, S. L., Thornton, C. R., Tasker, K., Jacob, C., Giles, G., Egan, M., and Talbot, N. J. 2004. A fungal metallothionein is required for pathogenicity of Magnaporthe grisea. Plant Cell 16:1575-1588.

Unger, C., Kleta, S., Jandl, G., and von Tiedemann, A. 2005. Suppression of the defence-related oxidative burst in bean leaf tissue and bean suspension cells by the necrotrophic pathogen Botrytis cinerea. J. Phytopathol. 153:15-26.

Valent, B., Farrall, L., and Chumley, F. G. 1991. Magnaporthe grisea genes for pathogenicity and virulence identified through a series of backcrosses. Genetics 127:87-101.

Wang, Z.-Y., Jenkinson, J. M., Holcombe, L. J., Soanes, D. M., VeneaultFourrey, C., Bhambra, G. K., and Talbot, N. J. 2005. The molecular biology of appressorium turgor generation by the rice blast fungus Magnaporthe grisea. Biochem. Soc. Trans. 33:384-388.

Wysong, D. R., Christin, L., Sugar, A. M., Robbins, P. W., and Diamond, R. D. 1998. Cloning and sequencing of a Candida albicans catalase gene and effects of disruption of this gene. Infect. Immun. 66:1953-1961.

Zhang, Z., Henderson, C., and Gurr, S. J. 2004. Blumeria graminis secretes an extracellular catalase during infection of barley: Potential role in suppression of host defence. Mol. Plant Pathol. 5:537-547. 